\title{
Histological and transcriptomic effects of 17a-methyltestosterone on zebrafish gonad development
}

\author{
Stephanie Ling Jie Lee ${ }^{1 *}$, Julia A. Horsfield², Michael A. Black³, Kim Rutherford', Amanda Fisher ${ }^{2}$ \\ and Neil J. Gemmell ${ }^{1}$
}

\begin{abstract}
Background: Sex hormones play important roles in teleost ovarian and testicular development. In zebrafish, ovarian differentiation appears to be dictated by an oocyte-derived signal via Cyp19a1a aromatase-mediated estrogen production. Androgens and aromatase inhibitors can induce female-to-male sex reversal, however, the mechanisms underlying gonadal masculinisation are poorly understood. We used histological analyses together with RNA sequencing to characterise zebrafish gonadal transcriptomes and investigate the effects of 17a-methyltestosterone on gonadal differentiation.

Results: At a morphological level, 17a-methyltestosterone (MT) masculinised gonads and accelerated spermatogenesis, and these changes were paralleled in masculinisation and de-feminisation of gonadal transcriptomes. MT treatment upregulated expression of genes involved in male sex determination and differentiation (amh, dmrt1, gsdf and wt1a) and those involved in 11-oxygenated androgen production (cyp 11 c1 and hsd1162). It also repressed expression of ovarian development and folliculogenesis genes (bmp15, gdf9, figla, zp2.1 and zp3b). Furthermore, MT treatment altered epigenetic modification of histones in zebrafish gonads. Contrary to expectations, higher levels of cyp 19a1a or fox/2 expression in control ovaries compared to MT-treated testes and control testes were not statistically significant during early gonad development (40 dpf).
\end{abstract}

Conclusion: Our study suggests that both androgen production and aromatase inhibition are important for androgen-induced gonadal masculinisation and natural testicular differentiation in zebrafish.

Keywords: Sex differentiation, Gonad differentiation, Androgens, Zebrafish

\section{Background}

Natural and synthetic steroid hormones influence gonadal sex differentiation and sex ratios in teleost fish [1-5]. In particular, androgens regulate testicular development, spermatogenesis, male secondary sex characteristics, sexual behaviour and maintenance of male sexual phenotype in teleosts $[4,6-9]$. The major natural androgen in teleost fish is 11-ketotestosterone [4], which is converted from androstenedione and testosterone via the steroidogenic enzymes $11 \beta$-hydroxylase (Cyp11c1) and $11 \beta$-hydroxysteroid dehydrogenase (Hsd11b2) [10-13]. The effects of these androgens are mediated by androgen receptors [10, 14].

\footnotetext{
* Correspondence: stephleelj@gmail.com

${ }^{1}$ Department of Anatomy, University of Otago, Dunedin, Otago, New Zealand Full list of author information is available at the end of the article
}

Synthetic androgens are structural mimics of the native androgen receptor ligands testosterone and 11-ketotestosterone (11-KT). They include 17 $\alpha$ methyltestosterone (MT), 17 $\alpha$-methyldihydrotestosterone, $17 \beta$-trenbolone, mibolerone and mesterolone [15]. Treatment with exogenous androgens at the labile stage during early development triggers testicular development, stimulates precocious spermatogenesis along with phenotypic and behavioural masculinisation, skews sex ratios towards males in gonochoristic fish [16-24] and accelerates female-to-male sex change in protogynous hermaphroditic fish [25-29]. Studies suggest that androgen-induced female-to-male phenotypic sex reversal is functional and persistent [30-33]. Androgen induction of female-to-male sex reversal $[15,34]$ is routinely used for sex control in 
aquaculture [35], with MT being the most frequently used androgen for production of all-male populations in commercial settings [15] because of its high masculinising potency [15].

Two hypotheses exist for the mode of action of androgens for induction of testicular differentiation: (1) indirect, via aromatase inhibition which reduces estrogen production [36-38] and (2) direct, via interactions with androgen receptor [36]. Prior studies of androgeninduced gonadal masculinisation in European seabass [39], Japanese flounder [19], groupers [26, 29], Nile tilapia [40] and rainbow trout [41-45] using candidate gene and microarray approaches [46] support the aromatase inhibition hypothesis. The gonadal masculinisation observed in zebrafish following treatment with aromatase inhibitor also strongly supports this hypothesis [38]. However, recent studies in tilapia and grouper implicate androgen receptor in androgen-induced phenotypic masculinisation [36, 47]. Overall, the molecular mechanisms underpinning androgen-induced gonadal masculinisation in fishes remain to be clarified.

Zebrafish (Danio rerio) is a popular toxicological model and has been used extensively to study the effects of endocrine-disrupting chemicals on gonad development and sexual phenotype [24, 30-32, 48-57]. The primary sex determining region present in wild zebrafish strains appear to have largely been lost in laboratory strains through the domestication process [58]. Almost all zebrafish in the world are derived from domesticated strains, with most from the $\mathrm{AB}$ strain and its derivatives except for the WIK strain. Domesticated zebrafish use a polygenic sex determination system [59] vulnerable to the effects of high temperature [60, 61], hypoxia [62], rearing density $[63,64]$, inbreeding, out-crossing $[65,66]$ and hormones [30]. Zebrafish is a juvenile hermaphrodite, wherein all individuals initially develop a nonfunctional 'juvenile ovary' [67-70]. Oocytes undergo apoptosis in juvenile ovaries of presumptive males during juvenile ovary-to-testis gonadal transformation [71]. In contrast, oocytes continue oogenesis and oocyte maturation in presumptive females [68] via unknown ovarian aromatase (Cyp19a1a)-mediated mechanisms [70]. Depending on the dosage, treatment with exogenous androgens can induce female-to-male sex reversal [24, 30-33] and paradoxical feminisation in zebrafish [72]. The $\operatorname{Tg}($ vas:egfp $)$ zebrafish line exhibits sexually dimorphic expression of green fluorescent protein which facilitates in vivo sex identification during early gonad development [73]. It has been used to study estrogenic effects in zebrafish [74].

Little is known about the direct transcriptional effects of MT during gonad masculinisation. In this study, we treated juvenile $T g$ (vas:egfp) transgenic zebrafish with $100 \mathrm{ng} / \mathrm{L}$ MT from 20 days post fertilisation (dpf) to 40 $\mathrm{dpf}$ and $60 \mathrm{dpf}$. These time points were selected to reflect the onset $(20 \mathrm{dpf})$ and completion $(40 \mathrm{dpf})$ of juvenile ovary-to-testis transformation as well as the onset of female puberty (60 dpf) in zebrafish $[68,69,75]$. RNA sequencing (RNA-Seq) was used to profile global gene expression patterns in MT-treated gonads. The gonadal transcriptomes of MT-treated zebrafish were compared with those of control zebrafish testes and ovaries to provide insights into the molecular basis for MT-induced gonadal masculinisation in zebrafish.

\section{Methods}

\section{Ethics statement}

This study was approved by the University of Otago Animal Ethics Committee (AEC No. 101/09). All experiments were performed in accordance with the Good Practice Guide for the use of animals in research, testing and teaching.

\section{Zebrafish husbandry}

Zebrafish were maintained according to Westerfield [76]. We used larval and juvenile transgenic zebrafish expressing an enhanced green fluorescent protein (EGFP) under the control of the vasa promoter, $\operatorname{Tg}($ vas:egfp), derived from the domesticated Tübingen/AB strains [73]. EGFP expression in $T g$ (vas:egfp) transgenic zebrafish enables visualisation and isolation of gonads before the gonads can be unequivocally distinguished from other tissues [77]. Higher levels of fluorescence are detected in ovaries than testes $[69,73]$, which can be used to distinguish the phenotypic sex of the fish.

\section{7a-methyltestosterone treatment}

$17 \alpha$-methyltestosterone (MT) was purchased from Sigma Aldrich (Sigma-Aldrich Sweden AB, Stockholm, Sweden) and dissolved in $100 \%$ ethanol to prepare stock solutions of $50 \mathrm{mg} / \mathrm{L}$. At 18 to $19 \mathrm{dpf}$, juvenile zebrafish were transferred from $4 \mathrm{~L}$ tanks into petri dishes where they were size-sorted by visual inspection. Zebrafish that were unusually small $(<5.5 \mathrm{~mm})$ or large $(>8.5 \mathrm{~mm})$ were removed. The remaining juvenile zebrafish (between 5.5 to $8.5 \mathrm{~mm}$ in length) were transferred into $4 \mathrm{~L}$ tanks containing $3.5 \mathrm{~L}$ of system water at a density of 20 individuals per tank.

For the MT exposure, the juvenile zebrafish were exposed to system water containing either $100 \mathrm{ng} / \mathrm{L}$ of MT dissolved in $0.0001 \%$ ethanol (100 ng/L MT) or $0.0001 \%$ ethanol alone (solvent control). Each exposure group consisted of 3 biological replicates comprising 20 juvenile zebrafish each. The exposure was performed continuously under a semi-static system for 20 or 40 days extending from $20 \mathrm{dpf}$ to $40 \mathrm{dpf}$ or 60 dpf. Water with equivalent concentrations of MT and ethanol was used to replace half of the water in 
each beaker every second day for the MT treatment and solvent control groups respectively.

\section{Determination of gonadal morphology and sex ratios}

At the termination of the treatment at $40 \mathrm{dpf}$ and 60 dpf, the juvenile zebrafish were sacrificed via snap chilling in ice water. EGFP expression of each zebrafish was observed under a Leica M205 FA fluorescence dissecting stereo microscope (Leica Microsystems, Bannockburn, Illinois, USA) to determine the gonadal sex of each fish and sex ratios for each exposure group. Between 18 to 24 fish per exposure group (comprising 6 to 8 fish from each of the 3 replicates per time point) were selected for histological analysis to confirm gonadal sex as determined by EGFP expression and to determine the developmental stages of each gonad. Whole zebrafish were fixed overnight in $10 \%$ neutral buffered formalin, dehydrated and embedded in paraffin. Haematoxylin and eosin-stained sections were examined under light microscopy to determine gonadal sex. Ovaries were classified as Stage I or Stage II [75], based on the absence or presence of Stage II oocytes containing cortical alveoli, respectively [78]. Testes were categorised into transition gonads, immature testes or mature testes. Gonads with basophilic apoptotic bodies and infiltration of stromal tissue were classified as transition gonads [68]. Testes were classified as immature or mature depending on the absence or presence of spermatozoa [79]. Spermatids differentiate into spermatozoa, through a series of morphological changes inclusive of nuclear compaction and flagellum formation, which are released into the seminiferous tubule lumen at the end of spermiogenesis [80].

\section{RNA isolation}

The juvenile zebrafish gonads were dissected and placed into aliquots of RNAlater (Invitrogen, Life Technologies GmbH / ThermoFisher Scientific, Darmstadt, Germany) or Lysis buffer (RLT buffer from an RNeasy Mini kit, Qiagen $\mathrm{GmbH}$, Hilden, Germany or RA1 lysis buffer from a Nucleospin RNA II kit, Macherey-Nagel GmbH \& Co. KG, Düren, Germany) and stored at $-80{ }^{\circ} \mathrm{C}$ for subsequent RNA isolation. The gonads from ten individuals per exposure group were pooled together for RNA extraction. Gonads were homogenized by passing through a 20 gauge needle or using 2 cycles of the TissueLyser II system (Qiagen $\mathrm{GmbH}$, Hilden, Germany) set at $20 \mathrm{~Hz}$ for 1 min per cycle.

RNA was isolated using an RNeasy Mini kit (Qiagen GmbH, Hilden, Germany) or a Nucleospin RNA II kit (Macherey-Nagel GmbH \& Co. KG, Düren, Germany) and eluted in 53ul of RNase-free water.

Three biological replicates of gonad pools consisting of 10 individuals each were generated for each exposure group (MT exposure and solvent control), sex (male or female) and time point (40 dpf or $60 \mathrm{dpf}$ ) (Fig. 1). The RNA samples were quantified and integrity was assessed

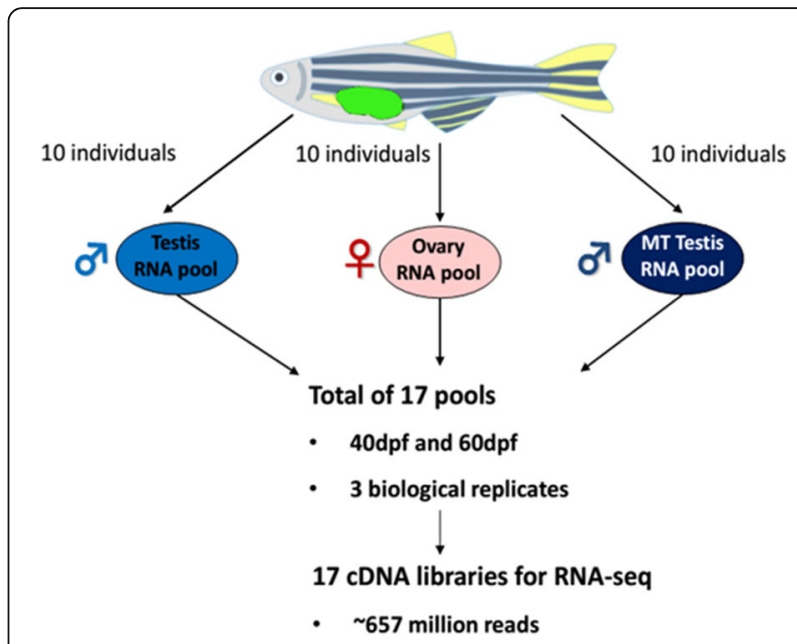

Fig. 1 General overview schematic of the zebrafish gonad RNA-Seq experiment. RNA was isolated from pools of gonads dissected from 10 individuals and subjected to RNA-Seq analyses. The gonads were pooled according to sex (male, female and masculinised male), developmental period tested (40 dpf and $60 \mathrm{dpf}$ ) and treatment group (solvent control and 17a-methyltestosterone treatment). Gonad RNA pools were analysed in triplicate

using the Agilent 2100 Bioanalyser (Agilent Technologies, Palo Alto, California, USA). RNA samples with RNA Integrity Numbers (RIN) $\geq 7.0$ (majority with RIN $\geq 8.0$ to 9.0) were used for RNA sequencing (RNA-Seq).

\section{RNA sequencing}

The Illumina TruSeq RNA sample preparation kit v2 (Illumina, Inc., San Diego, California, USA) was used with $1 \mu \mathrm{g}$ of starting total RNA from the gonad pools to generate $100 \mathrm{bp}$ paired end (PE) cDNA libraries in accordance to the manufacturer's instructions. Three biological replicates were generated for each exposure group except for the $40 \mathrm{dpf}$ MT-treated testis group, which was limited to two biological replicates. A total of seventeen gonad tagged cDNA libraries were sequenced: 40CO1-3 (40 dpf control ovary pools 1 to 3), 40CT1-3 (40 dpf control testis pools 1 to 3 ), 40MT1-2 (40 dpf MT-treated testis pools 1 and 2), 60CO1-3 (60 dpf control ovary pools 1 to 3 ), 60CT1-3 (60 dpf control testis pools 1 to 3), and 60MT1-3 (60 dpf MT-treated testis pools 1 to 3), on a HiSeq 2000 sequencer (Illumina, Inc., San Diego, California, USA) at the New Zealand Genomics Limited Otago facility (Otago Genomics and Bioinformatics Facility, University of Otago, Dunedin, Otago, New Zealand) (Table 1). The raw sequencing reads have been submitted to NCBI Sequence Read Archive (SRA; http://www.ncbi.nlm.nih.gov/sra) repository under accession number SRP102493.

\section{Read annotation, mapping, assembly and quantification} The quality of the raw reads was assessed using the FastQC software [81] and the sequencing QC report tool 
Table 1 Gonad cDNA libraries generated for RNA sequencing

\begin{tabular}{|c|c|c|c|c|}
\hline Stage & Treatment & Gonad & Replicates & Replicate names \\
\hline $40 \mathrm{dpf}$ & Solvent control & Ovary & 3 & $\begin{array}{l}40 \mathrm{CO} 1,40 \mathrm{CO} 2 \\
40 \mathrm{CO} 3\end{array}$ \\
\hline $40 \mathrm{dpf}$ & Solvent control & Testes & 3 & $\begin{array}{l}40 C T 1,40 C T 2 \\
40 C T 3\end{array}$ \\
\hline $40 \mathrm{dpf}$ & 17a- methyltestosterone & Testes & 2 & 40MT1, 40MT2 \\
\hline $60 \mathrm{dpf}$ & Solvent control & Ovary & 3 & $\begin{array}{l}60 \mathrm{CO} 1,60 \mathrm{CO} 2, \\
60 \mathrm{CO}^{2}\end{array}$ \\
\hline $60 \mathrm{dpf}$ & Solvent control & Testes & 3 & $\begin{array}{l}\text { 60CT1, 60CT2, } \\
60 \mathrm{CT} 3\end{array}$ \\
\hline $60 \mathrm{dpf}$ & 17a- methyltestosterone & Testes & 3 & $\begin{array}{l}\text { 60MT1, 60MT2, } \\
60 \mathrm{MT3}\end{array}$ \\
\hline
\end{tabular}

in CLC Genomics Workbench 6.0.2 software (Qiagen Bioinformatics $\mathrm{GmbH}$, Hilden, Germany). CLC Genomics Workbench was used to trim low quality sequences (phred-based error probability threshold of 0.05) and to remove TruSeq adapter sequences from the raw reads. Trimmed reads from each pool were mapped and aligned to the Zebrafish Zv9 reference sequence (ftp://ftp.ensembl.org/pub/current_fasta/danio_rerio/dna/) from the ENSEMBL database. Annotation of the Zebrafish ZV9 reference genome was performed using the respective GTF file (ftp://ftp.ensembl.org/pub/current_gtf/danio_rerio/) using the CLC Genomics Workbench 6.0.2 'Annotate with GFF/GTF' plug-in. In order to correct for differences in transcript length and library size, transcript abundance was normalised using the reads per kilobase per million mapped reads (RPKM) method [82]. Transcripts with RPKM value greater than or equal to 1.0 (RPKM $\geq 1.0$ ) were regarded as expressed. Transcripts with RPKM value greater than or equal to 5.0 ( $R P K M \geq 5.0)$ were regarded as reliably expressed.

\section{Identification of differentially expressed transcripts}

Differentially expressed transcripts were identified in the zebrafish gonad transcriptomes across different conditions (sex, age, MT treatment and gonad phenotype) using the proportions-based beta-binomial Baggerley's test [83]. The RPKM data was transformed by adding a constant (1.0) and then normalised using a quantile normalisation. Transcripts responsive to MT were identified via pairwise comparisons of MT-treated gonads with age-matched control ovaries and testes. Transcripts were regarded as differentially expressed if they complied with (1) the normalised fold change threshold of greater than or equal to two for upregulated transcripts and smaller than or equal to minus two for downregulated transcripts ( $\geq 2.0$-fold) and (2) a false discovery rate (FDR) corrected $p$-value of $\leq 0.05(p \leq 0.05)$ [84].

To investigate the overall gene expression patterns across the treatment conditions and phenotypic sexes, we performed hierarchical clustering using Pearson correlation distance with complete linkage, and Principal Component Analyses (PCA), as implemented and visualised in CLC Genomics Workbench. The sets of differentially expressed transcripts that overlapped or differed between treatments were visualised using Venn diagrams plotted using the Venny software (http://bioinfogp.cnb. csic.es/tools/venny/).

\section{Gene ontology enrichment analysis of differentially expressed genes}

Gene Ontology Consortium (GO) [85] functional annotation terms and categories were assigned to the differentially expressed genes with the 'Add Annotations' tool of CLC Genomics Workbench. The GO terms, IDs and annotations were downloaded from the Gene Ontology database in the 20 May 2013 release of the ZFIN Zebrafish GO gene association file (http://www.geneontology.org/ GO.downloads.annotations.shtml).

\section{Functional enrichment and network pathway analysis}

Biological functions and metabolic pathways significantly overrepresented among the differentially expressed genes were identified using Metacore (GeneGo, Thomson Reuters, Carlsbad, California, USA). This approach utilizes Fisher's exact test with an FDR correction for multiple testing. Differentially expressed genes were defined as genes where (1) the absolute value for normalised fold change was greater than or equal to two and (2) the FDR adjusted $p$-value was less than 0.05 [84].

\section{Validation of differentially expressed genes using quantitative RT-PCR}

Quantitative real-time PCR (qRT-PCR) was conducted on 12 differentially expressed transcripts identified from the RNA-seq data. TaqMan Gene Expression Assays (Applied Biosystems, Thermo Fisher Scientific, Waltham, Massachusetts, USA) specific to our genes of interest were used with a Stratagene Mx3000P (Agilent Technologies, Santa Clara, California, USA) Real Time-PCR thermal cycler. Each qPCR reaction was performed in triplicate. $\beta$-actin 1, ribosomal protein L13 alpha $(r p l 13 \alpha)$ and eukaryotic translation elongation factor 1 alpha 1 , like 1 (eef1a1l1) were tested for their utility as the reference genes for this study. Previous studies have shown that the expression levels of these genes remain fairly constant across different developmental periods, treatment conditions, sexes and tissue types in zebrafish [86, 87]. In this study, minor differences in $\beta$-actin 1 expression were found between different pooled ovary samples however the expression levels of $r p l 13 \alpha$ and eefla1ll were consistent across different tissue types (adult testes and ovaries) as previously reported [88] (data not shown). eef1a1l1 gave the highest average expression stability values with the geNorm algorithm [89].The 
comparative CT method ( $\Delta \Delta \mathrm{Ct})$ was used to determine relative gene expression compared to the reference gene eefla1l1. The female ovary groups $(40 \mathrm{CO}$ and $60 \mathrm{CO}$ ) were used as the calibrator for calculation of relative expression. Relative expression was expressed as fold change (Fold Change $=2-\Delta \Delta \mathrm{Ct}$ ). Complete details of the genes selected, TaqMan Gene Expression Assays and $\mathrm{qPCR}$ cycling conditions are provided in Additional file 1.

\section{Results}

\section{Sex ratios and gonad histology of control zebrafish}

Sex ratios were determined via visualisation of EGFP fluorescence intensity of $\mathrm{Tg}$ (vas:egfp) zebrafish under a fluorescence microscope. Gonads exhibiting low and high EGFP fluorescence were classified as testes and ovaries respectively $[69,73]$. Male and female zebrafish were present in the control at $40 \mathrm{dpf}$ and $60 \mathrm{dpf}$. The control sex ratios were $32 \%$ males at $40 \mathrm{dpf}$ and $45 \%$ males at $60 \mathrm{dpf}$ (Additional file 2). The mortality rates were very low $(\leq 10 \%)$ for the control with no significant difference $(p$-value $>0.05)$ observed between replicates (Additional file 2).

To determine the effects of MT on zebrafish gonad development, we treated juvenile zebrafish with $100 \mathrm{ng} / \mathrm{L}$ MT from $20 \mathrm{dpf}$ to $40 \mathrm{dpf}$ and $60 \mathrm{dpf}$. All MT-treated zebrafish had testes except for one individual at $40 \mathrm{dpf}$ (40 dpf: 59/60 individuals and 60 dpf: 98/98 individuals) (Additional file 2) suggesting that MT treatment had stimulated gonadal masculinisation.

The EGFP fluorescence signal was considerably fainter in $40 \mathrm{dpf}$ testes than for $40 \mathrm{dpf}$ ovaries. A few gonads (4/4 males) appeared to be undergoing gonadal transformation into testes at $40 \mathrm{dpf}$ and were classified as presumptive testes (Fig. 2a). Several residual bodies indicative of apoptotic oocytes were present. The remaining oocytes in these gonads had lost their tight contact and showed signs of degeneration including shrinkage, irregularity of shape and basophilic cytoplasm. Stromal tissue had infiltrated the inter-oocyte spaces. In a few individuals, the germ cells had re-arranged to form tubule-like structures.

Regardless of the stage of ovarian development, intense EGFP fluorescence signals were detected in ovaries of $40 \mathrm{dpf}$ and $60 \mathrm{dpf}$ zebrafish. At $40 \mathrm{dpf}$, all control females analysed using histological examination possessed ovaries at early stages of development (14/14 individuals). These immature ovaries were predominantly filled with tightly packed Stage IB oocytes although pre-meiotic Stage IA oogonia were located at the caudal edges of the ovaries (Fig. 2b). Most MT-treated zebrafish had mature testes at $40 \mathrm{dpf}(17 / 22$ individuals) (Fig. 2e). One was undergoing juvenile ovary-to-testis transformation (Fig. 2c). The remaining three individuals possessed immature testes (Fig. 2d). In contrast, control males had testes which had just completed juvenile ovaryto-testis transformation (4/4 individuals) (Fig. 2a).

Similar to $40 \mathrm{dpf}$ control ovaries, the $40 \mathrm{dpf}$ MTtreated ovary contained Stage IB oocytes (Fig. 2f). Early range-finding experiments testing different periods of MT exposure suggested that occasionally a few individuals exposed to MT from $20 \mathrm{dpf}$ to $40 \mathrm{dpf}$ or $50 \mathrm{dpf}$ were refractory to the masculinising effects of MT treatment (data not shown).

Testes at $60 \mathrm{dpf}$ barely exhibited any EGFP fluorescence. There were three types of $60 \mathrm{dpf}$ control testes: presumptive (2/10 males), immature (4/10 males) and mature testes (4/10 males) (Fig. 3a - c). $60 \mathrm{dpf}$ presumptive testes resembled $40 \mathrm{dpf}$ presumptive testes which were populated with a few degenerative oocytes and large volumes of stromal tissue (Fig. 3a). Most $60 \mathrm{dpf}$ control testes (8/10 individuals) were at a more advanced stage of differentiation than those at $40 \mathrm{dpf}$ (Fig. 3b and c). Well-differentiated spermatogonial cysts containing spermatogonia, spermatocytes and spermatids were observed in $60 \mathrm{dpf}$ control immature and mature testes (Fig. $3 \mathrm{~b}$ and $\mathrm{c}$ ). The lumens of mature $60 \mathrm{dpf}$ control testes were filled with mature spermatozoa (Fig. 3c).

Considerable individual differences in the extent of ovarian development were seen in $60 \mathrm{dpf}$ control females. A few ovaries (6/13 females) consisted primarily of Stage IB oocytes (Fig. 3d). Others (7/13 females) contained oocytes at more advanced stages of development such as Stage II cortical alveolar oocytes (Fig. 3e and f).

Greater numbers of $60 \mathrm{dpf}$ MT-treated zebrafish possessed mature testes (21/21 individuals) (Fig. 3g) than control males (17/22 individuals) whose testes were at various stages of spermatogenesis (Fig. $3 \mathrm{a}-\mathrm{c}$ ).

\section{Global sex differences in gonadal gene expression patterns}

To elucidate the genes involved in zebrafish sexual differentiation, we compared the transcriptomes of developing zebrafish testes and ovaries using RNA Sequencing. Gonads were classified as testes or ovaries on the basis of EGFP expression in the juvenile $T g$ (vas:egfp) zebrafish as described above. Greater numbers of gene transcripts were present in the zebrafish testis than zebrafish ovary at both $40 \mathrm{dpf}$ and $60 \mathrm{dpf}$ (Additional file 3). About 12,000 transcripts were consistently expressed $(\mathrm{RPKM} \geq 5)$ in zebrafish testes (Table 2). In contrast, $\sim 8000$ transcripts were expressed in zebrafish ovaries at $40 \mathrm{dpf}$ and $60 \mathrm{dpf}$ (Table 2). 

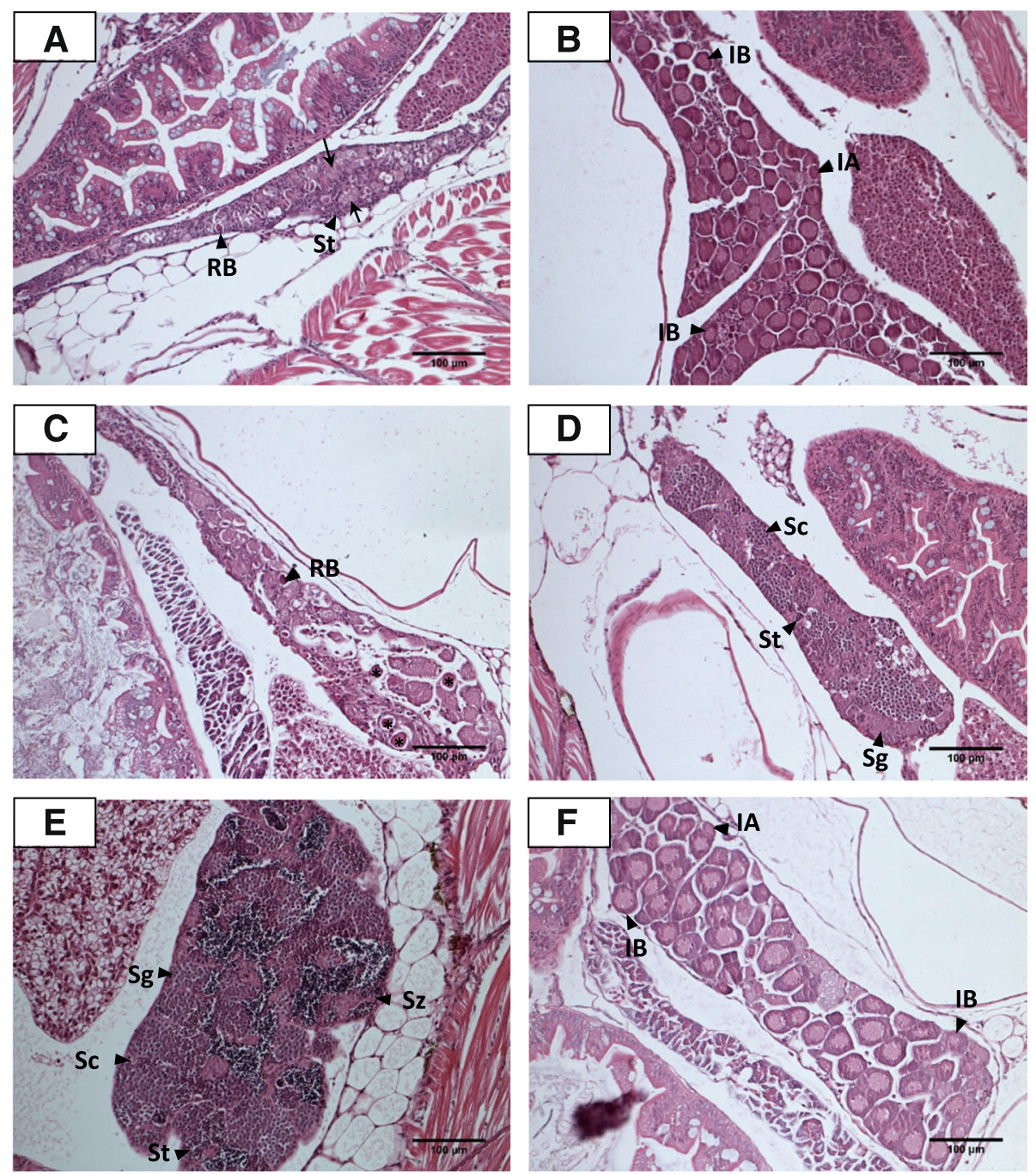

Fig. 2 Histological analysis of gonads of $40 \mathrm{dpf}$ control (a and $\mathbf{b}$ ) and MT-treated juvenile zebrafish (c-f). a Presumptive testis characterised by the presence of residual bodies (RB), an indicator of oocyte degeneration, infiltration of stromal (Str) cells and spermatogenic tubule-like structures $(\rightarrow)$. b Ovary with Stage IA (IA) and Stage IB (IB) oocytes. c Transforming gonad. d Immature testis with spermatogonia (Sg), spermatocytes (Sc) and spermatids (St). e Mature testis possessing spermatogonia (Sg), spermatocytes (Sc), spermatids (St) and spermatozoa (Sz). f Ovary with Stage IA (IA) and Stage IB (IB) oocytes. Bar $=100 \mu \mathrm{m}$

Developing zebrafish testes and ovaries showed striking differences in the numbers of differentially expressed transcripts at $40 \mathrm{dpf}$ and $60 \mathrm{dpf}$. At $40 \mathrm{dpf}$, over 5000 transcripts were differentially expressed ( $\geq 2$-fold, FDRadjusted $p$-value $\leq 0.05$ ) between testes and ovaries (Fig. 4a and b). Of these, half were preferentially expressed in testes and half were expressed more highly in ovaries. Significantly greater numbers of sexually dimorphic transcripts were identified at $60 \mathrm{dpf}$ than at $40 \mathrm{dpf}$. At $60 \mathrm{dpf}$, the number of sex differentially expressed transcripts had risen to almost 8500 (Fig. 4c and d). Similar to what was observed at $40 \mathrm{dpf}$, the proportion of testis-enriched transcripts and ovary-enriched transcripts were approximately the same at $60 \mathrm{dpf}$.

\section{Characterisation of the testicular differentiation programme}

Transcripts with pro-male roles in fishes (dmrt1, amh, gsdf and sox $9 a$ ) and genes encoding steroidogenic enzymes for 11-oxygenated androgen production (cyp11c1, cyp17a1, hsd11b2, nr5a1a and star) and androgen receptivity (ar) were more highly expressed in control testes than control ovaries during gonadal transformation and testicular differentiation (Table 3, Additional file 4). We also found upregulation of genes involved in gammaaminobutyric acid (gabrr2b and $g l s b$ ) and dopamine (drd2l) signalling, immune response (il1b, mif and irf9) and encoding histone variants ( $h 1 f 0, h 1 f x, h 2 a f y 2$, histh $1 l$ and hist $2 h 2 l$ ) in control testes (CT) compared to control 

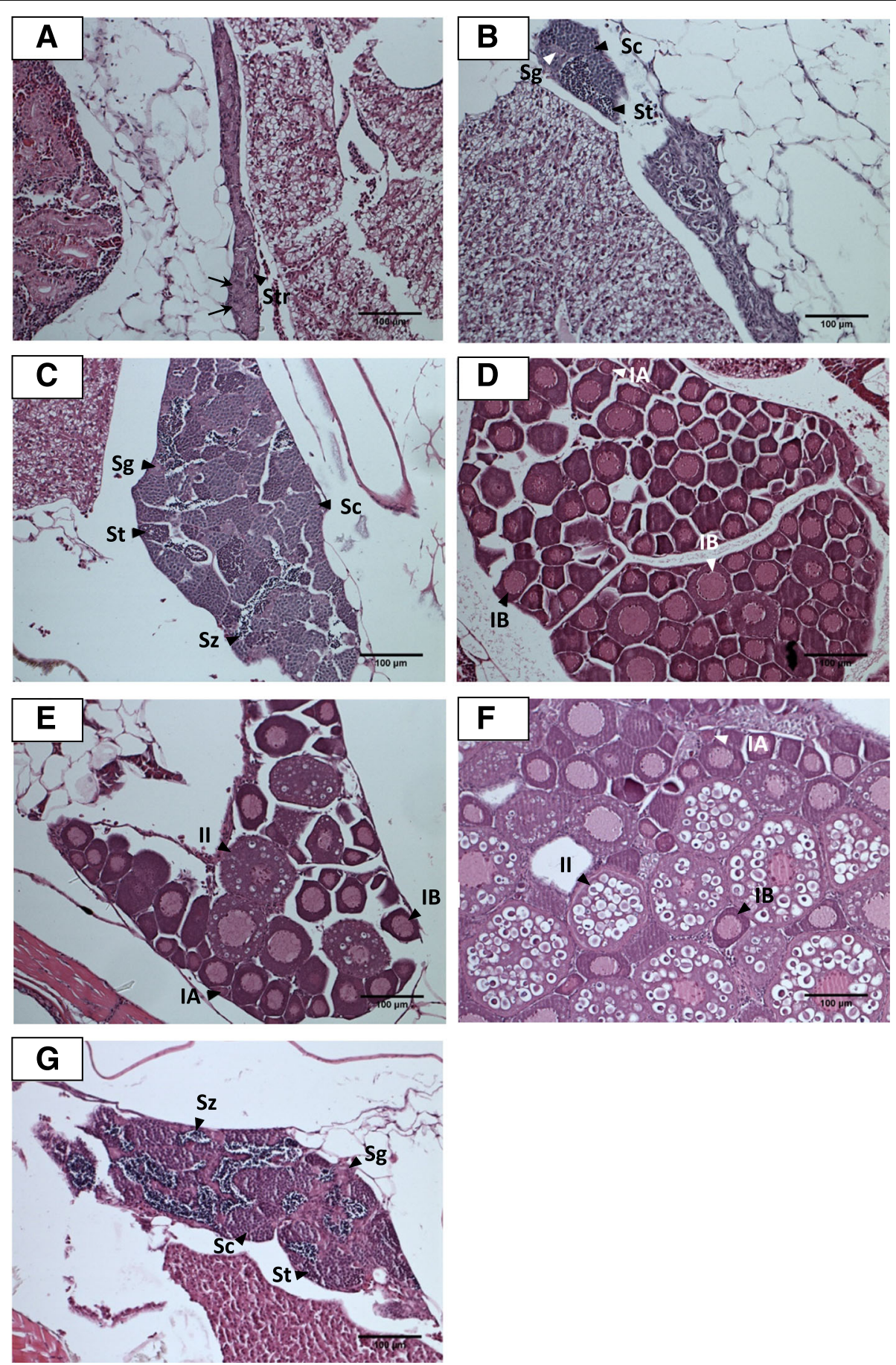

Fig. 3 Histological analysis of gonads of $60 \mathrm{dpf}$ untreated control (a - $\mathbf{f})$ and MT-treated juvenile zebrafish (g). a Presumptive testis comprising infiltration of stromal (Str) cells and spermatogenic tubule-like structures $(\rightarrow)$. b Immature testis containing spermatogonia (Sg), spermatocytes (Sc) and spermatids (St). c Mature testis containing spermatogonia (Sg), spermatocytes (Sc), spermatids (St) and spermatozoa (Sz). d Ovary with Stage IA (IA) and Stage IB (IB) oocytes. e Ovary with Stage I IA (IA), Stage IB (IB) and Stage II (II) oocytes. f Ovary with Stage I IA (IA), Stage IB (IB) and Stage II (II) oocytes. g Mature testis possessing spermatogonia (Sg), spermatocytes (Sc), spermatids (St) and spermatozoa (Sz). Bar $=100 \mu \mathrm{m}$

ovaries (CO) (Table 3, Additional file 4). The gene names and IDs can be found in Additional file 5.

There were developmental stage-specific differences in expression levels of testis-biased transcripts (Table 3).
Gata4, pdgfra and tp53 expression in testes were significantly higher in testes than ovaries at $40 \mathrm{dpf}$ (early testicular development) but not $60 \mathrm{dpf}$ (Table 3, Additional file 4). The magnitude of testis-biased expression of several 
Table 2 Average expression levels (RPKM values) in developing gonads at $40 \mathrm{dpf}$ and $60 \mathrm{dpf}$. RPKM $\geq 1$ was defined as the RPKM threshold for expressed transcripts. RPKM $\geq 5$ was defined as the RPKM threshold for reliable detection of expressed transcripts. RPKM, reads per kilobase per million mapped reads. 40CO, 40 dpf control ovaries. 40CT, $40 \mathrm{dpf}$ control testes. 40MT, $40 \mathrm{dpf}$ MT-treated testes. 60CO, $60 \mathrm{dpf}$ control ovaries. 60CT, $60 \mathrm{dpf}$ control testes. 60MT, $60 \mathrm{dpf}$ MT-treated testes

\begin{tabular}{lll}
\hline Group & RPKM $\geq 1$ & RPKM $\geq 5$ \\
\hline $40 \mathrm{CO}$ & 12,617 & 8047 \\
$60 \mathrm{CO}$ & 12,269 & 8191 \\
$40 \mathrm{CT}$ & 18,906 & 11,692 \\
$60 \mathrm{CT}$ & 19,016 & 11,975 \\
$40 \mathrm{MT}$ & 18,311 & 11,489 \\
$60 \mathrm{MT}$ & 19,028 & 11,865 \\
\hline
\end{tabular}

pro-male genes (dmrt1, gsdf, wt1a, nrOb1 and $a m h$ ) was significantly higher at $40 \mathrm{dpf}$ than $60 \mathrm{dpf}$ (Table 3, Additional file 4). Genes encoding sperm tail proteins septin3, septin8b and $o d f 3 b$ had been upregulated in testes compared to ovaries at $60 \mathrm{dpf}$ but not $40 \mathrm{dpf}$ (Table 3, Additional file 4, Additional file 6 ).

\section{Characterisation of the ovarian differentiation program}

Transcripts implicated in teleost fish female sex determination, ovarian development, oogenesis and folliculogenesis (foxl2, cyp19a1a, lhx8a, figla, bmp15, gdf9, zp21. and $z p 3 b$ ) were more highly expressed in control ovaries than control testes (Table 4, Additional file 4). The gene names and IDs can be found in Additional file 5 .

We observed stage-dependent differences in ovarian expression patterns. Genes involved in fish folliculogenesis (bmp15, figla, gdf9, lhx8a, zp2.1, zp3b and vldr) had been more highly expressed in ovaries than testes from $40 \mathrm{dpf}$ (Table 4). However, the expression levels of several pro-female transcripts (foxl2, cyp19a1a, esr $2 a$ and $v \operatorname{tg} 1$ ) had only been significantly upregulated in ovaries compared to testes at $60 \mathrm{dpf}$ (Table 4). We also found higher expression of several genes involved in histone modification and DNA methylation (ehmt1a, ehmt2 and dnmt1) and encoding histone variants ( $h 2 a f x$ and $h 1 m$ ) in ovaries compared to testes (Table 4).

The expression patterns of a few transcripts with established roles in female sex determination and sex differentiation (sox9b, ctnnb1, ctnnbip1, wnt4a and rspo1) were not identified as sexually dimorphic in this study (Additional file 4).

\section{Methyltestosterone induces masculinisation and de-feminisation of the gonadal transcriptome}

Substantially fewer transcripts were differentially expressed between MT-treated testes and control testes in comparison with control ovaries, particularly at $60 \mathrm{dpf}$ (Table 5). Although more than five thousand transcripts were differentially expressed in MT-treated gonads compared to control ovaries at $40 \mathrm{dpf}$ (Table 5), only about a thousand differentially expressed transcripts separated the transcriptomes of MT-treated gonads from control testes transcriptomes (Table 5). The transcripts differentially expressed in $40 \mathrm{dpf}$ MT-treated testes compared to control ovaries overlapped considerably with those differentially expressed between control testes and control ovaries (Fig. $4 \mathrm{a}$ and b).

At $60 \mathrm{dpf}$, the number of transcripts differentially expressed in MT-treated testes relative to control ovaries rose to seven and a half thousand (Table 5). At the same time, the number of transcripts differentially expressed between the MT-treated gonads and control testes fell to 20 (Table 5).

Marked changes indicating masculinisation and defeminisation of the gonad transcriptome were observed in testes treated with MT to $40 \mathrm{dpf}$ and $60 \mathrm{dpf}$. Among the two and a half thousand transcripts with upregulated expression in $40 \mathrm{dpf}$ MT-treated testes relative to $40 \mathrm{dpf}$ control ovaries (Table 5), 61\% were more highly expressed in control testes than control ovaries i.e., testis-enriched (Fig. 4a). Many of these transcripts have established roles in vertebrate testicular development and spermatogenesis (Table 6, Additional file 7).

Of nearly three thousand transcripts showing downregulated expression in $40 \mathrm{dpf}$ MT-treated testes compared to $40 \mathrm{dpf}$ control ovaries (Table 4 ), $74 \%$ were more highly expressed in control ovaries than control testes i.e., ovaryenriched (Fig. 4b). Genes previously implicated in fish folliculogenesis were included among the transcripts more highly expressed in ovaries compared to MT-treated testes (Table 7, Additional file 7). The proportions of transcripts with testis-enriched and ovary-enriched expression in 60 dpf MT-treated testes rose to $92 \%$ of the three and a half thousand upregulated transcripts (Fig. 4c and Table 5) and $87 \%$ of the four thousand downregulated transcripts (Fig. $4 \mathrm{~d}$ and Table 5), respectively. This confirms that the correlation between the expression profiles of MT-treated gonads and control testes increased with developmental stage.

\section{Methyltestosterone induces acceleration of spermatogenesis}

The overlap between the testis-biased transcripts and transcripts showing upregulated expression in MTtreated testes relative to ovaries at $40 \mathrm{dpf}$ was higher for $60 \mathrm{dpf}$ control testes (96\%) than $40 \mathrm{dpf}$ control testes (61\%) (Fig. 5a). A similar pattern was observed for the transcripts which exhibited downregulated expression in 40 dpf MT-treated testes. A greater proportion of transcripts exhibiting downregulated expression in $40 \mathrm{dpf}$ MT-treated testes was shared with $60 \mathrm{dpf}$ control testes (89\%) than $40 \mathrm{dpf}$ control testes (74\%) (Fig. 5b). A comparison between the transcriptomes of $40 \mathrm{dpf}$ MT-treated 

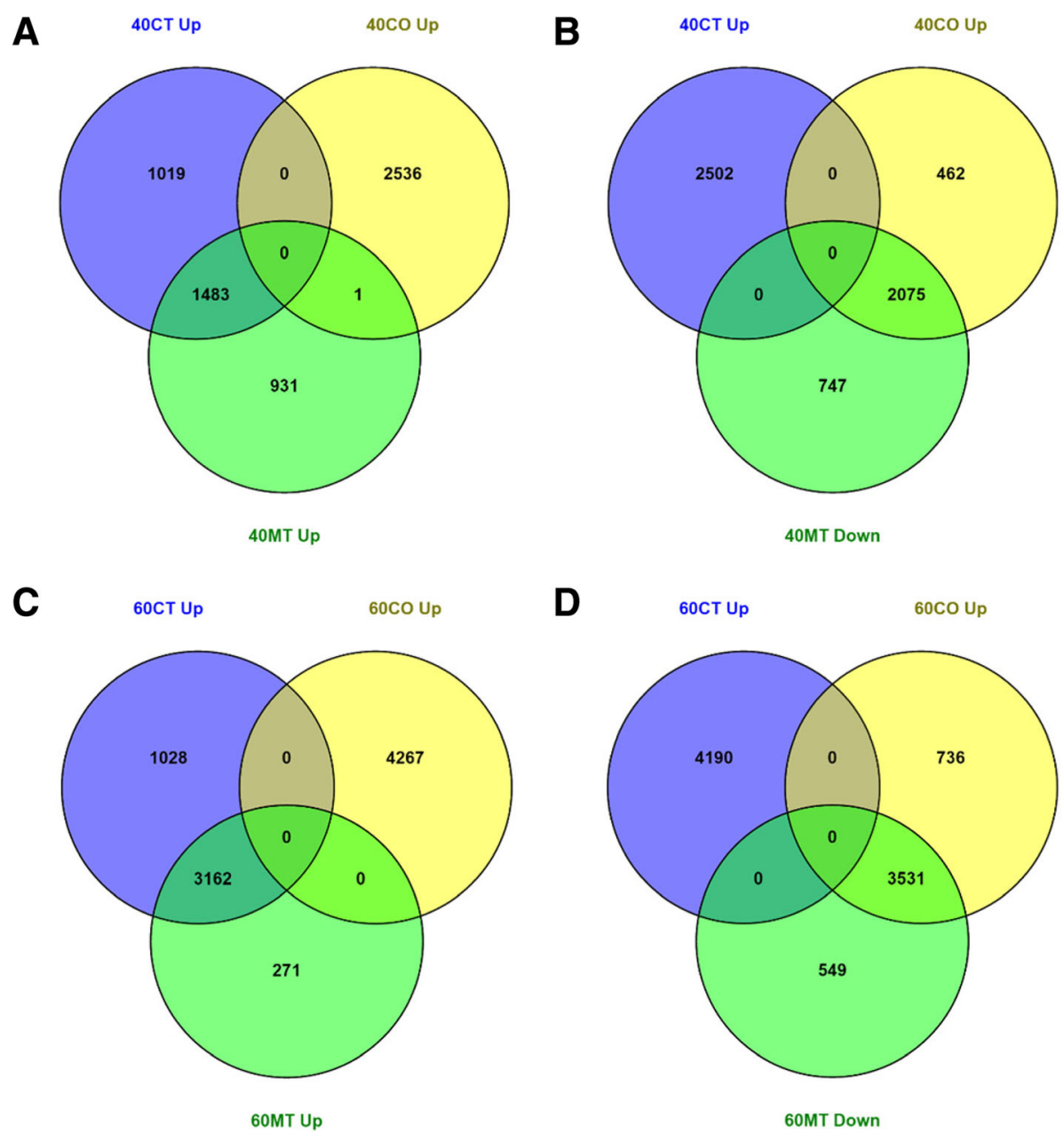

Fig. 4 Comparison of differentially expressed genes in MT-treated zebrafish testes with testis-enriched and ovary-enriched genes of control zebrafish ovaries and testes. $n=3$ pools of 10 individuals each. a Venn diagram of numbers of genes which showed upregulated expression in $40 \mathrm{dpf}$ MT-treated testes (40MT) overlapped with $40 \mathrm{dpf}$ testes (40CT) and $40 \mathrm{dpf}$ ovaries (40CO). b Venn diagram of numbers of genes which showed downregulated expression in $40 \mathrm{dpf}$ MT-treated testes (40MT) overlapped with $40 \mathrm{dpf}$ testes (40CT) and $40 \mathrm{dpf}$ ovaries (40CO). c Venn diagram of numbers of genes which showed upregulated expression in $60 \mathrm{dpf}$ MT- treated testes (40MT) overlapped with $60 \mathrm{dpf}$ testes (60CT) and 60 dpf ovaries (60CO). $\mathbf{d}$ Venn diagram of numbers of genes which showed downregulated expression in $60 \mathrm{dpf}$ MT-treated testes (40MT) overlapped with $60 \mathrm{dpf}$ testes $(60 \mathrm{CT})$ and $60 \mathrm{dpf}$ ovaries (60CO)

testes and $60 \mathrm{dpf}$ control testes revealed a difference of just 136 differentially expressed transcripts (Additional file 8).

The pattern continued at $60 \mathrm{dpf}$ where $92 \%$ of transcripts exhibiting upregulated expression in $60 \mathrm{dpf}$ MT-treated testes overlapped with $60 \mathrm{dpf}$ testis-biased transcripts compared to $55 \%$ for $40 \mathrm{dpf}$ testis-biased transcripts (Fig. 5c). $87 \%$ of transcripts with downregulated expression in 60 dpf MT-treated testes compared to $60 \mathrm{dpf}$ control ovaries was shared with $60 \mathrm{dpf}$ control testis as compared to $56 \%$ for $40 \mathrm{dpf}$ control testis (Fig. 5d).

The minor differences in the genetic cascades of 40 dpf MT-treated testes and $60 \mathrm{dpf}$ control testes concurs with the gonad histological data which suggested that
$17 \alpha$-methyltestosterone had accelerated testicular development (Fig. 2 and Fig. 3).

\section{Methyltestosterone switches gonad transcription to the male program}

The pathways enriched with genes exhibiting sexually dimorphic expression in zebrafish testes and ovaries were markedly different (Additional file 9). Similarly, the pathways overrepresented in MT-treated testes were considerably different from those in ovaries (Additional file 9). There was, however, substantial overlap between the pathways overrepresented in testes and MT-masculinized gonads, particularly at $60 \mathrm{dpf}$ (Additional file 9). 
Table 3 Expression profiles of genes involved in testicular differentiation and spermatogenesis. 40CO, $40 \mathrm{dpf}$ control ovaries. 40CT, $40 \mathrm{dpf}$ control testes. 60CO, $60 \mathrm{dpf}$ control ovaries. 60CT, $60 \mathrm{dpf}$ control testes

\begin{tabular}{|c|c|c|c|c|}
\hline \multirow{2}{*}{\multicolumn{2}{|c|}{$\frac{\text { No. Gene name }}{\text { Testis-Enriched Gen }}$}} & \multirow{2}{*}{$\begin{array}{l}\text { Gene ID } \\
\text { es }\end{array}$} & \multicolumn{2}{|c|}{ Fold change for control gonads } \\
\hline & & & $40 C T / 40 C O$ & $60 \mathrm{CT} / 60 \mathrm{CO}$ \\
\hline \multicolumn{5}{|c|}{ Male sex determination } \\
\hline 1 & $a m h$ & NM_001007779 & 129.92 & 72.07 \\
\hline 2 & $d m r t 1$ & NM_205628 & 13.89 & 23.43 \\
\hline 3 & gsdf & NM_001114668 & 141.09 & 69.01 \\
\hline \multicolumn{5}{|c|}{ Sertoli cell differentiation } \\
\hline 4 & gata4 & NM_131236 & 4.31 & n.s. \\
\hline 5 & sox9a & NM_131643 & 4.27 & 3.56 \\
\hline \multicolumn{5}{|c|}{ Leydig cell differentiation } \\
\hline 6 & pdgfra & NM_131459 & 2.81 & n.s. \\
\hline \multicolumn{5}{|c|}{ Steroidogenesis } \\
\hline 7 & ar & NM_001083123 & 3.38 & n.s. \\
\hline 8 & cyp11c1 & NM_001080204 & 40.77 & 61.48 \\
\hline 9 & cyp17a1 & NM_212806 & 4.84 & 2.63 \\
\hline 10 & esr2b & NM_174862 & 11.38 & 7.92 \\
\hline 11 & hsd11b2 & NM_212720 & 32.13 & 19.24 \\
\hline 12 & nr5ala & NM_131794 & 5.17 & 4.05 \\
\hline 13 & star & NM_131663 & 70.58 & 117.91 \\
\hline \multicolumn{5}{|c|}{ GABA and dopamine signalling } \\
\hline 14 & gabrr2b & XM_692394.7 & 8.25 & 23.26 \\
\hline 15 & $d r d 21$ & NM_197935.1 & n.s. & 2.46 \\
\hline \multicolumn{5}{|c|}{ Spermiogenesis } \\
\hline 16 & $k / h / 10 a$ & XM_002665116 & n.s. & 16.97 \\
\hline 17 & odf3b & NM_199958 & n.s. & 16.38 \\
\hline 18 & tekt1 & NM_001007397 & 25.00 & 177.52 \\
\hline \multicolumn{5}{|c|}{ Septin signalling } \\
\hline 19 & sept3 & NM_001024418 & n.s. & 6.14 \\
\hline 20 & sept8b & NM_001083566 & n.s. & 8.13 \\
\hline \multicolumn{5}{|c|}{ Histone variants } \\
\hline 21 & hifo & NM_199552.1 & 61.83 & 258.58 \\
\hline 22 & $h i f x$ & NM_199276.1 & 16.43 & 25.91 \\
\hline 23 & h2afy2 & NM_001025502.1 & 14.10 & 21.92 \\
\hline 24 & histh11 & NM_001017660.2 & 10.67 & 10.43 \\
\hline 25 & hist2h2l & NM_200117.1 & 5.78 & 7.30 \\
\hline \multicolumn{5}{|c|}{ Immune response } \\
\hline 26 & mif & NM_001043321.1 & 2.32 & 2.42 \\
\hline 27 & $i l 1 b$ & NM_212844.2 & 2.38 & 4.23 \\
\hline 28 & irf9 & NM_205710.2 & 4.29 & 4.34 \\
\hline \multicolumn{5}{|c|}{ Others } \\
\hline 29 & $d k k 3 b$ & NM_001089545 & 9.03 & 2.67 \\
\hline 30 & tp53 & NM_001271820 & 2.55 & n.s. \\
\hline
\end{tabular}

'Cell cycle', 'reproduction - progesterone-mediated oocyte maturation' and 'transcription' pathways were highly enriched in zebrafish ovaries during early ovarian development (40 dpf) (Additional file 9). Zebrafish testes showed an enrichment of genes involved in 'cytoskeleton remodelling', and 'immune response', 'TGF $\beta$ signalling' and 'G-protein signalling' pathways at $40 \mathrm{dpf}$ (Additional file 9).

Genes related to 'cell cycle,'reproduction - progesteronemediated oocyte maturation,' development-WNT signalling pathway' and 'protein folding and maturation_Angiotensin system maturation' pathways were highly overrepresented in $60 \mathrm{dpf}$ ovaries (Additional file 9). A significant overrepresentation of genes required for 'cytoskeleton remodelling' and 'G-protein signalling' were observed in $60 \mathrm{dpf}$ testes (Additional file 9).

While $40 \mathrm{dpf}$ zebrafish ovaries were highly enriched in genes for 'cell cycle', 'development' and 'transcription' pathways, MT-treated testes were enriched in genes involved in 'immune response', 'cytoskeleton remodelling' and different 'cell cycle' pathways (Additional file 9).

At $60 \mathrm{dpf}$, canonical 'Wnt signalling', 'integrin-mediated cell adhesion and migration', 'progesterone-mediated oocyte maturation' pathways were highly overrepresented in ovaries (Additional file 9). $60 \mathrm{dpf}$ MT-treated testes were significantly enriched in 'oxidative phosphorylation', 'immune response' and 'cell cycle' pathways (Additional file 9).

Mitotic 'cell cycle' and nucleotide metabolism pathways were overrepresented in $40 \mathrm{dpf}$ MT-treated testes (Additional file 9). In contrast, there was significant overrepresentation of pathways involved in 'apoptosis', Brcal mediated regulation of transcription, the synthesis of cortisone, cortisol and androgen signalling in $40 \mathrm{dpf}$ control testes (Additional file 9).

Although $60 \mathrm{dpf}$ testes were highly enriched in 'DNA replication', 'relaxin signalling', nucleotide metabolism and 'fatty acid biosynthesis' pathways (Additional file 9), no pathways were overrepresented in $60 \mathrm{dpf}$ MT-treated testes.

To validate the RNA-Seq results, qPCR was conducted on 12 differentially expressed genes from four pairwise comparisons based on sex and treatment: 40CT vs. $40 \mathrm{CO}, 40 \mathrm{MT}$ vs. $40 \mathrm{CO}, 60 \mathrm{CT}$ vs. $60 \mathrm{CO}$ and $60 \mathrm{MT}$ vs. $60 \mathrm{CO}$ (Additional file 10). The direction of fold-change for the two platforms agreed for most of the genes (10/ 12 genes tested) (Additional file 10) confirming the accuracy of the RNA-Seq data.

\section{Discussion}

In this study, we investigated the effects of MT treatment on zebrafish gonadal transcriptomes during gonadal differentiation. We found that MT treatment masculinises gonadal transcriptomes and is accompanied by morphological changes consistent with male gonad 
Table 4 Expression profiles of genes involved in ovarian differentiation and folliculogenesis. 40CO, $40 \mathrm{dpf}$ control ovaries. $40 \mathrm{CT}, 40 \mathrm{dpf}$ control testes. 60CO, $60 \mathrm{dpf}$ control ovaries. $60 \mathrm{CT}, 60 \mathrm{dpf}$ control testes

\begin{tabular}{|c|c|c|c|c|}
\hline No. & Gene name & Gene ID & \multicolumn{2}{|c|}{ Fold change for control gonads } \\
\hline \multicolumn{3}{|c|}{ Ovary-enriched genes } & $40 C T / 40 C O$ & $60 \mathrm{CT} / 60 \mathrm{CO}$ \\
\hline \multicolumn{5}{|c|}{ Female sex determination } \\
\hline 1 & foxL2a & NM_001045252 & n.s. & -3.11 \\
\hline 2 & foxL2b & NP_001304690 & n.s. & -2.72 \\
\hline \multicolumn{5}{|c|}{ Folliculogenesis } \\
\hline 3 & bmp15 & NM_001020484 & -13.76 & -19.85 \\
\hline 4 & figla & NM_198919 & -17.47 & -18.88 \\
\hline 5 & gdf9 & NM_001012383 & -11.26 & -14.52 \\
\hline 6 & $1 \mathrm{~h} \times 8 a$ & NM_001003980 & -7.81 & -13.17 \\
\hline
\end{tabular}

Zona pellucida proteins

$\begin{array}{lllll}7 & z p 2.1 & \text { BC124100 } & -13.63 & -27.82 \\ 8 & z p 36 & \text { NM_131696 } & -16.28 & -25.36\end{array}$

Steroid hormone and prostaglandin signalling

$\begin{array}{cllll}9 & \text { cypilal } & \text { NM_152953 } & -10.79 & -15.81 \\ 10 \text { cyp19a1a } & \text { NM_131154 } & \text { n.s. } & -3.23 \\ 11 \text { esr2a } & \text { NM_180966 } & \text { n.s. } & -2.82 \\ \text { Vitellogenesis } & & & \\ 12 \text { vtg1 } & \text { NM_001044897.3 } & \text { n.s. } & -2.50\end{array}$

Granulosa cell function

13 sox11b NM_131337 $\quad-6.21 \quad-11.95$

Wnt signalling

14 ctnnb1 NM_131059 n

15 ctnnbip1 NM_131594 n.

16 lef1 NM_131426 -3.

17 tcf7 NM_001012389 n.

18 rspol NM_001002352 n.

19 wnt4a NM_001040387 n.s

20 wnt11

NM_001144804 -3.05

Histone variants

$\begin{array}{lllll}21 & \text { h1m } & \text { NM_183071.2 } & -14.28 & -29.14 \\ 22 & \text { h2afx } & \text { NM_201073.1 } & -6.09 & -8.17\end{array}$

Histone modification and DNA methylation

\begin{tabular}{lllll}
23 & ehmt1a & NM_001030131.2 & -3.63 & -6.24 \\
24 & ehmt2 & NM_001113615.1 & n.s. & -2.13 \\
25 & dnmt1 & NM_131189.2 & -5.34 & -5.02 \\
\hline
\end{tabular}

development. MT activated pro-male gene expression (dmrt1, amh and $g s d f$ ) and induced steroidogenic enzymes required for production of 11-oxygenated androgens (cyp11c1 and $h s d 11 b 2)$. MT treatment also repressed gonadal expression of pro-female genes cyp19a1a, foxl2, bmp15 and gdf9, particularly during folliculogenesis at 60 dpf. Taken together, our data suggest that MT-induced
Table 5 Identification of genes differentially expressed ( $\geq 2$-fold, FDR-adjusted $p$-value $\leq 0.05)$ in the gonads in response to methyltestosterone treatment at $40 \mathrm{dpf}$ and $60 \mathrm{dpf}$ using Baggerley's test [83]. CO, control ovaries. CT, control testes. MT, MT-treated testes

\begin{tabular}{llllllll}
\hline \multicolumn{1}{c}{ Experimental variable } & \multicolumn{3}{c}{ Differentially expressed } \\
\hline Stage & Experiment & Testis & Ovary & MT & Total & Up & Down \\
$40 \mathrm{dpf}$ & CO vs MT & X & X & X & 5237 & 2415 & 2822 \\
$40 \mathrm{dpf}$ & CT vs MT & X & & X & 1222 & 284 & 938 \\
$60 \mathrm{dpf}$ & CO vs MT & X & X & X & 7513 & 3433 & 4080 \\
$60 \mathrm{dpf}$ & CT vs MT & X & & X & 20 & 9 & 11 \\
\hline
\end{tabular}

masculinisation involves both activation of androgen receptor-mediated pathways and inhibition of aromatase.

\section{MT activates pro-male gene expression}

We found strong upregulation of $d m r t 1$ expression in both control and MT-treated testes in this study, consistent with its essential role in zebrafish testis development [90]. In tilapia, upregulation of $d m r t 1$ expression is associated with androgen-induced gonadal masculinisation [91]. Similarly, dmrt1 expression increased following MT treatment of XX medaka [92], and upon temperaturedependent induction of gonadal masculinisation in European seabass [93], tilapia [94], medaka [95] and pejerrey [96]. We suggest that the activation of $d m r t 1$ may be one of the key steps underpinning hormonal and environmental gonadal masculinisation in fish.

MT treatment increased amh expression in zebrafish gonads. Amh operates downstream of $d m r t 1$ in zebrafish [90] and is highly expressed in zebrafish transforming testes where it may inhibit cyp19a1a expression [13, 97]. Defective amh/amhr signalling in medaka causes excessive germ cell proliferation and male-to-female sex reversal in half of XY hotei mutants $[98,99]$. The data are collectively consistent with the idea that amh signalling operates downstream of MT to repress female patterns of germ cell proliferation in teleosts.

MT treatment upregulated $g s d f$ gonadal expression in zebrafish, consistent with a recent study in medaka demonstrating that MT induced gsdf expression in gonads [92]. In medaka, gsdf is involved in early testicular differentiation and is a key regulator of male-specific gene expression [100-103]. Gsdf expression has not been characterised in zebrafish. Our results suggest $g s d f$ may be important for zebrafish testicular differentiation.

Interestingly, we found higher expression of gabrr $2 b$ and $d r d 2 l$ in control and MT-treated testes than control ovaries. Gamma-aminobutyric acid (GABA) and dopamine are important regulatory neurotransmitters in the hypothalamus-pituitary-gonadal axis. In teleost fish, both GABA and dopamine modulate production of 
Table 6 Selection of genes which showed upregulated expression in MT-treated testes (MT) compared to ovaries (CO). 40CO, $40 \mathrm{dpf}$ control ovaries. 40MT, $40 \mathrm{dpf}$ MT-treated testes. 60CO, $60 \mathrm{dpf}$ control ovaries. 60MT, $60 \mathrm{dpf}$ MT-treated testes

\begin{tabular}{lll}
\hline No. Gene name Gene ID & Fold change for control gonads \\
\hline Testis-Enriched Genes & $40 \mathrm{MT} / 40 \mathrm{CO} \quad 60 \mathrm{MT} / 60 \mathrm{CO}$
\end{tabular}

Male sex determination

$\begin{array}{lllll}1 & \text { amh } & \text { NM_001007779 } & 66.56 & 74.09 \\ 2 & \text { dmrt1 } & \text { NM_205628 } & 10 & 27.38 \\ 3 & \text { gsdf } & \text { NM_001114668 } & 115.21 & 120.57\end{array}$

Sertoli cell differentiation

$\begin{array}{lllll}4 & \text { gata4 } & \text { NM_131236 } & \text { n.s. } & \text { n.s. } \\ 5 & \text { sox9a } & \text { NM_131643 } & \text { n.s. } & \text { n.s. }\end{array}$

Leydig cell differentiation

$\begin{array}{cllll}6 & \text { pdgfra } & \text { NM_131459 } & \text { n.s. } & \text { n.s. } \\ \text { Steroidogenesis } & & & \\ 7 \text { ar } & \text { NM_001083123 } & \text { n.s. } & \text { n.s. } \\ 8 \text { cyp11c1 } & \text { NM_001080204 } & 8.8 & 43.34 \\ 9 \text { cyp17a1 } & \text { NM_212806 } & \text { n.s. } & \text { n.s. } \\ 10 \text { esr2b } & \text { NM_174862 } & 7.25 & 7.33 \\ 11 & \text { hsd11b2 } & \text { NM_212720 } & 7.40 & 16.49 \\ 12 & \text { nr5a1a } & \text { NM_131794 } & \text { n.s. } & \text { n.s. } \\ 13 \text { star } & \text { NM_131663 } & \text { 22.17 } & 83.7\end{array}$

GABA and dopamine signalling

$\begin{array}{lllll}14 & \text { gabrr2b } & \text { XM_692394.7 } & 12.43 & 25.29 \\ 15 & \text { drd2l } & \text { NM_197935.1 } & \text { n.s. } & 2.69\end{array}$

Spermiogenesis

$\begin{array}{cllll}16 & \text { klhl10a } & \text { XM_002665116 } & 29.96 & 31.04 \\ 17 \text { odf3b } & \text { NM_199958 } & 14.52 & 34.00 \\ 18 \text { tekt1 } & \text { NM_001007397 } & 296.47 & 385.53 \\ \text { Septin signalling } & & & \\ 19 \text { sept3 } & \text { NM_001024418 } & 5.89 & 6.57 \\ 20 \text { sept8b } & \text { NM_001083566 } & 11.92 & 11.60\end{array}$

Histone variants

\begin{tabular}{cllll}
21 & hifo & NM_199552.1 & 322.24 & 493.16 \\
22 & h1fx & NM_199276.1 & 18.18 & 32.26 \\
23 & h2afy2 & NM_001025502.1 & 12.11 & 26.18 \\
24 & histh1l & NM_001017660.2 & 9.44 & 12.75 \\
25 & hist2h2l & NM_200117.1 & 5.24 & 7.68 \\
Immune response & & & \\
26 & mif & NM_001043321.1 & n.s. & 2.15 \\
27 & illb & NM_212844.2 & n.s. & 5.03 \\
28 irf9 & NM_205710.2 & n.s. & 5.51 \\
Others & & & \\
29 & dkk3b & NM_001089545 & 4.89 & 4.91 \\
30 & tp53 & NM_001271820 & n.s. & n.s. \\
\hline
\end{tabular}

Table 7 Selection of genes which showed downregulated expression in MT-treated testes (MT) compared to ovaries (CO). 40CO, $40 \mathrm{dpf}$ control ovaries. 40MT, $40 \mathrm{dpf}$ MT-treated testes. 60CO, $60 \mathrm{dpf}$ control ovaries. 60MT, $60 \mathrm{dpf}$ MT-treated testes

\begin{tabular}{lll}
\hline No. Gene name Gene ID & Fold change for control gonads \\
\hline Ovary-enriched genes & $40 \mathrm{MT} / 40 \mathrm{CO}$ & $60 \mathrm{MT} / 60 \mathrm{CO}$ \\
Female sex determination & &
\end{tabular}

\begin{tabular}{|c|c|c|c|c|}
\hline 1 & foxL2a & NM_001045252 & n.s. & n.s. \\
\hline 2 & foxL2b & NP_001304690 & n.s. & n.s. \\
\hline \multicolumn{5}{|c|}{ Folliculogenesis } \\
\hline 3 & bmp15 & NM_001020484 & -8.35 & -26.10 \\
\hline 4 & figla & NM_198919 & -7.76 & -20.07 \\
\hline 5 & $g d f 9$ & NM_001012383 & -7.13 & -18.24 \\
\hline 6 & Ihx $\times 8 a$ & NM_001003980 & -3.74 & -18.32 \\
\hline
\end{tabular}

Zona pellucida proteins

$\begin{array}{cllll}7 & \text { zp2.1 } & \text { BC124100 } & -5.71 & -33.66 \\ 8 & \text { zp3b } & \text { NM_131696 } & -6.27 & -37.89 \\ \text { Steroid hormone } & & & \\ 9 & \text { cyp11a1 } & \text { NM_152953 } & -4.68 & -15.93 \\ 10 & \text { cyp19a1a } & \text { NM_131154 } & \text { n.s. } & \text { n.s. } \\ 11 \text { esr2a } & \text { NM_180966 } & -3.00 & -3.57 \\ \text { Vitellogenesis } & & & \\ 12 \text { vtg1 } & \text { NM_001044897.3 } & \text { n.s. } & \text { n.s. }\end{array}$

Granulosa cell function

113 sox116 NM_131337 $\quad-5.33 \quad-12.80$

Wnt signalling

$\begin{array}{lllll}14 & \text { ctnnb1 } & \text { NM_131059 } & \text { n.s } & \text { n.s } \\ 15 & \text { ctnnbip1 } & \text { NM_131594 } & \text { n.s } & -2.09 \\ 16 & \text { lef1 } & \text { NM_131426 } & -3.01 & -6.31 \\ 17 & \text { tcf7 } & \text { NM_001012389 } & \text { n.s } & \text { n.s } \\ 18 & \text { rspo1 } & \text { NM_001002352 } & \text { n.s } & \text { n.s } \\ 19 & \text { wnt4a } & \text { NM_001040387 } & \text { n.s } & \text { n.s } \\ 20 & \text { wnt11 } & \text { NM_001144804 } & \text { n.s } & -2.26\end{array}$

Histone variants

$\begin{array}{lllll}21 & \text { h1 } m & \text { NM_183071.2 } & -5.40 & -43.53 \\ 22 & \text { h2afx } & \text { NM_201073.1 } & -4.04 & -7.85\end{array}$

Histone modification and DNA methylation

\begin{tabular}{lllll}
23 & ehmt1a & NM_001030131.2 & -4.58 & -7.73 \\
24 & ehmt2 & NM_001113615.1 & -2.81 & -2.49 \\
25 & dnmt1 & NM_131189.2 & -4.32 & -6.46 \\
\hline
\end{tabular}

hypothalamic gonadotrophin releasing hormone and pituitary gonadotrophins [104-110].

GABA A receptor has been implicated in Leydig cell proliferation in mice $[111,112]$. GABA may regulate androgen production in rodent testes [113-115]. Dopamine 

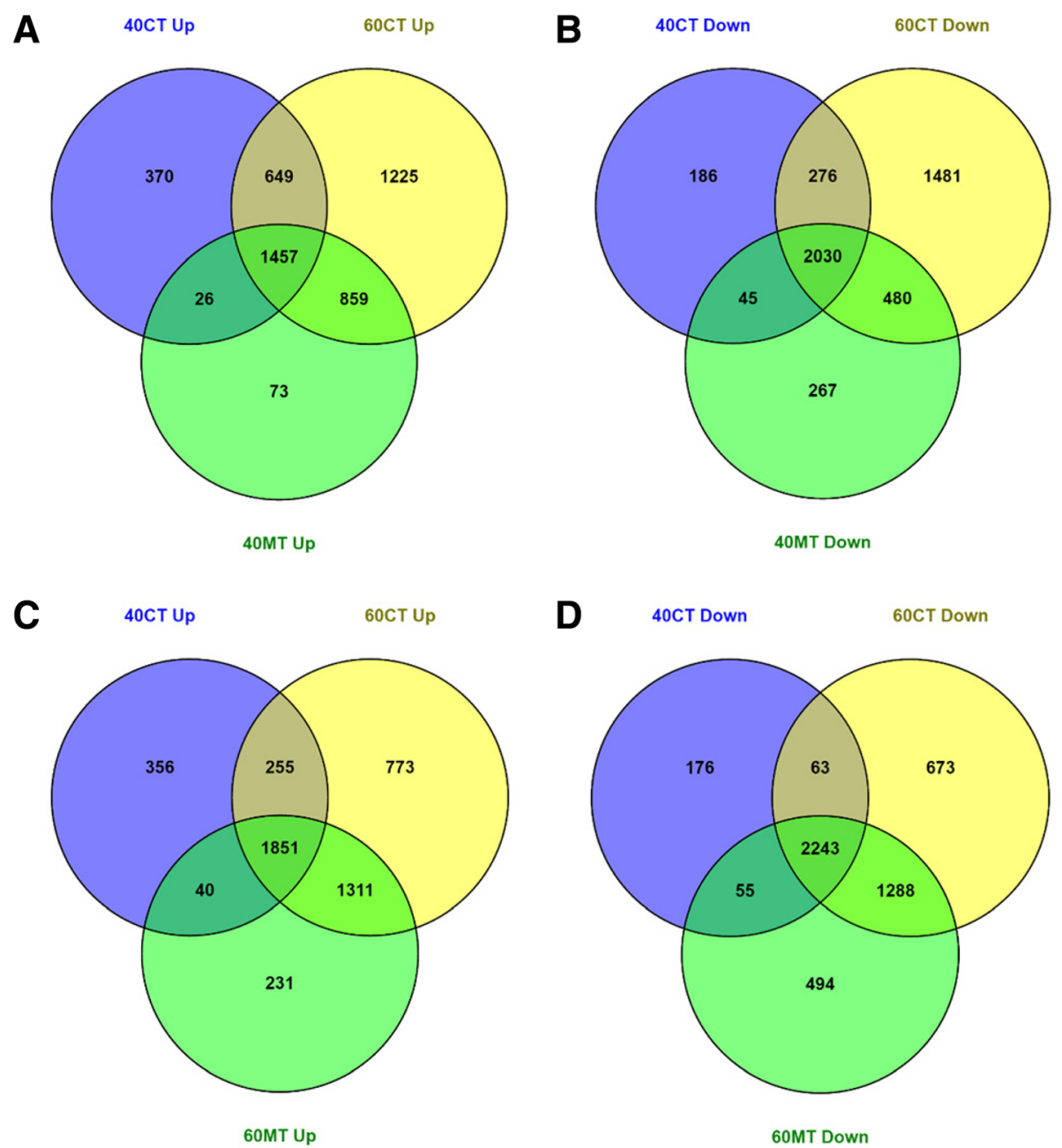

Fig. 5 Comparison of differentially expressed genes in MT-treated zebrafish testes with testis-enriched genes of $40 \mathrm{dpf}$ and $60 \mathrm{dpf}$ control testes. $n=3$ pools of 10 individuals each with the exception of $40 \mathrm{MT}$ which comprised of 2 pools. a Venn diagram of numbers of genes which showed upregulated expression in $40 \mathrm{dpf}$ MT-treated testes (40MT) overlapped with numbers of genes upregulated in $40 \mathrm{dpf}$ testes (40CT) and $60 \mathrm{dpf}$ testes (60CT). b Venn diagram of numbers of genes which showed downregulated expression in $40 \mathrm{dpf}$ MT-treated testes (40MT) overlapped with numbers of genes downregulated in $40 \mathrm{dpf}$ testes (40CT) and $60 \mathrm{dpf}$ testes (60CT). c Venn diagram of numbers of genes which showed upregulated expression in $60 \mathrm{dpf}$ MT-treated testes (60MT) overlapped with numbers of genes upregulated in $40 \mathrm{dpf}$ testes (40CT) and $60 \mathrm{dpf}$ testes (60CT). $\mathbf{d}$ Venn diagram of numbers of genes which showed downregulated expression in $60 \mathrm{dpf}$ MT-treated testes (60MT) overlapped with numbers of genes downregulated in $40 \mathrm{dpf}$ testes (40CT) and $60 \mathrm{dpf}$ testes (60CT)

type 2 receptor has been reported in mammalian testes and male germ cells where it regulates sperm capacitation and motility [116, 117]. Although dopamine antagonists are used with gonadotrophin analogues (eg. Ovaprim) for induced spawning in aquaculture [118, 119], the role of dopamine signalling in fish spermatogenesis has not been studied. Our expression data suggests that GABAergic and dopamine signalling may be important for teleost testicular development.

Genes encoding the cytokines mif and illb had been upregulated in control and MT-testes compared to control ovaries. GO pathways involved in immune response pathways had been significantly upregulated in control testes and MT-treated testes compared to control ovaries. MIF-JAB1 and interleukin 1 signalling pathways were significantly over-represented in testes. MIF and IL-1 $\beta$ are cytokines involved in innate immunity and inflammation. Both act as paracrine factors responsible for regulation of testosterone production by Leydig cells in rat testes [120-124]. MIF is produced by Leydig cells and Sertoli cells where it is involved in the cross-talk between Leydig cells and testicular seminiferous tubule somatic cells, spermagonial cell migration and may be involved in regulation of sex hormone production and spermiogenesis [125-128]. IL-1 $\beta$ is expressed in mice testicular germ and somatic cells [129]. Interleukin 1 is 
important for Sertoli cell proliferation [130, 131]. Our data suggests that mif and $i l 1 b$ may mediate androgeninduced sex reversal in zebrafish.

Unexpectedly, we found that a few irf genes which included irf 9 were more highly expressed in control and MT-treated testes than control ovaries. A truncated form of irf 9 was identified as the master sex determining gene in rainbow trout [132]. Our expression data supports Yano et al. 2014's hypothesis that interferon signalling may be involved in teleost testicular development and spermatogenesis. It may be worthwhile to study possible roles of interferon in teleost testes.

In this study, MT upregulated gene expression for several histone variants (h1fo, h1fx, h2afy2, histh1l and hist $2 h 2 l$ ) compared to ovaries. Interestingly, gene expression of these histones had also been significantly upregulated during heat-induced masculinisation of zebrafish [61]. Testis-specific histone variants eg. histone $\mathrm{HI}$ variant H1t [133], histone H2B variant TSH2B [134, 135], histone $\mathrm{H} 3$ variant $\mathrm{H} 3 \mathrm{t}$ [136, 137], histone H1 like [138] have been identified in mammals. Some of the testis-specific histone variants have been implicated in mammalian spermatogenesis [134, 136, 138, 139]. Chromatin compaction during spermiogenesis requires epigenetic modification of histones [139, 140], via mechanisms including chromatin modification via exchange of histone variants and histone modification [141].

\section{MT represses pro-female gene expression}

MT treatment caused strong inhibition of bmp15 expression in zebrafish gonads. Bmp15 is necessary for activation of cyp19a1a expression and therefore estrogen production in granulosa cells surrounding Stage II oocytes [142]. Loss of cyp19a1a expression in juvenile zebrafish ovaries leads to germ cell apoptosis and female-to-male sex reversal [70]. Our results suggest that MT treatment may suppress ovarian development by preventing bmp15-mediated cyp19a1a expression in granulosa cells. MT treatment also strongly inhibited genes involved in Wnt signalling pathways. Wnt signalling is important for ovarian differentiation in zebrafish [143], medaka [144, 145] and rainbow trout [146] so its repression is consistent with masculinisation.

We found that MT downregulated expression of genes involved in chromatin histone modification and DNA methylation pathways in epigenetics (dnmt1, hdac11, ehmt1a and ehmt2) compared to control ovaries. Interestingly, hdac11 and ehmt2 expression had been upregulated with heat-induced masculinisation in European seabass [93]. The expression levels of the histone variants $h 2 a f x$ and $h 1 m$ had been lower in MT-treated testes than ovaries, similar to reported female-biased expression in Olive flounder [147].

\section{How do sex steroid hormones cause gonadal masculinisation?}

Consistent with observations during MT-induced gonadal masculinisation in tilapia [40], we found cyp11a1, hsd3b1 and cyp 19a1a transcripts were reduced when juvenile zebrafish were treated with MT. We also found that MT treatment actively promoted cyp $11 c 1$ and $h s d 11 b 2$ expression in zebrafish gonads. Cyp11c1 works together with hsd11b2 to convert androgens into 11-oxygenated androgens. This contrasts with studies in rainbow trout which found downregulated cyp11c1 expression during androgen-induced gonadal masculinisation using $11 \beta$ hydroxyandrostenedione $[41,45]$. Despite both being 11KT precursors, MT and 11 $\beta$-hydroxyandrostenedione produce different intermediate products with different androgenic potencies. It is possible that MT induces gonadal masculinisation by different mechanisms to those employed by $11 \beta$-hydroxyandrostenedione, perhaps via these differing intermediate products.

Our results suggest that androgen production may also be important for natural juvenile ovary-to-testis gonadal transformation in zebrafish. Cyp11c1 and hsd11b2 expression was higher in transforming testes than juvenile ovaries during juvenile ovary-to-testis transformation at 40 dpf. This concurs with the higher levels of cyp11c1 expression previously reported in juvenile ovotestes compared to juvenile ovaries amid zebrafish juvenile ovary-to-testis transformation [13, 143]. This indicates that the steroidogenic enzymes required for androgen production are active during early stages of juvenile ovary-to-testis transformation. We found that pathways involved in cortisol biosynthesis from cholesterol and cortisone biosynthesis and metabolism and androgen receptor nuclear signalling were higher in transforming testes than MT-treated testes at $40 \mathrm{dpf}$. Cortisol and androgen signalling pathways were shown to be linked in high temperature-induced masculinisation of pejerrey via $h s d 11 b 2$ [148]. This suggests that $h s d 11 b 2$-mediated androgen production may be important for testicular differentiation in zebrafish.

Taken together, our data show that increased 11oxygenated androgen production and decreased aromatase expression may be equally important for MT-induced gonadal masculinisation in zebrafish.

\section{MT alters germ cell proliferation rates in juvenile ovaries}

The juvenile ovary-to-testis transformation process in zebrafish is characterised by oocyte apoptosis [71]. In zebrafish, genes in pro-apoptotic pathways (tp53) have been implicated in testicular differentiation [149], while anti-apoptotic pathways (NF- $\mathrm{kB}$ ) promote ovarian differentiation [150]. Partial or complete germ cell depletion in gonads invariably leads to gonadal masculinisation $[88,149,151,152]$. 
Gonadal hormones can regulate germ cell apoptosis in vertebrates [153, 154] including teleost fish [5]. In zebrafish, $17 \alpha$-ethinylestradiol and fadrozole can alter germ cell apoptosis and proliferation during gonad differentiation [54]. Several genes that regulate cell apoptosis and proliferation are also involved in gonadal sexual differentiation [155]. A threshold of germ cells or meiotic oocytes is required for ovarian development in zebrafish $[152,156]$ such that the phenotypic sex in zebrafish depends critically on the number of germ cells in gonads during early development $[88,152,157]$. How germ cell numbers maintain female identity is not fully understood.

We observed that MT treatment downregulates genes involved in DNA replication in early $\mathrm{S}$ phase, Estrogen Receptor 1 (Esr1) regulation of G1/S phase, mitogenic action of Estradiol /Esr1 and ligand-dependent activation of the Estrogen receptor 1/ Specificity Protein (Esr1/Sp) pathway in $40 \mathrm{dpf}$ juvenile ovaries. We suggest that androgens may induce female-to-male sex reversal via modulation of germ cell proliferation rates. MT-induced repression of estrogen-activated mitotic pathways in juvenile ovaries leads us to hypothesise that MT may trigger female-to-male sex reversal via inhibition of estrogen-activated proliferation of oocytes in zebrafish ovaries. This would reduce oocyte numbers below the threshold, leading to activation of male-specific gene expression in gonadal somatic cells.

In this study, we used transgenic zebrafish derived from domesticated zebrafish strains. Domesticated zebrafish strains use polygenic sex determination $[58,59]$ and are sensitive to environmental and hormonal factors $[32,53,61,63,158]$. The sensitivity of domesticated zebrafish strains to hormonal effects on gonad development render them good models for determining the mode of action of androgens on induction of testicular differentiation. Evidence comparing Atlantic Silverside utilising genetic sex determination (GSD) and temperature sex determination (TSD) suggest that expression of cyp19a1a, a key gene in ovarian development, was earlier, stronger, more sexually dimorphic and less temperature sensitive in GSD strains than TSD strains [159]. It is possible that the thresholds of environmental and hormonal sensitivity for key sex determining loci may vary between wild (ZZ/ZW sex determination) and domesticated (polygenic sex determination) zebrafish strains. Different mechanisms may be activated for androgen-induced sex reversal of wild zebrafish populations. Future studies using wild strains would facilitate elucidation of the pathways involved. Due to the polygenic mode of sex determination and lack of sex-linked markers in domesticated zebrafish strains, we were unable to distinguish between male and female zebrafish prior to morphological gonadal differentiation. Therefore, the MT treatment was conducted on zebrafish with unknown proportions of male and female sexual genotypes. This resulted in production of populations comprising males and neo-males. The development and use of all-male and allfemale zebrafish lines [160] in future studies would help further clarify whether MT treatment has different effects on genetic males and females.

\section{Conclusion}

In conclusion, zebrafish MT-induced gonadal masculinisation involves activation of pro-male gene expression and repression of pro-female gene expression. Steroidogenic enzymes critical for 11-oxygenated androgen production (cyp11c1 and hsd11b2) and estrogen production (cyp19a1a) were among genes differentially expressed in response to MT treatment suggesting that androgen production and aromatase inhibition appear to both be important for zebrafish androgen-induced gonadal masculinisation. MT-induced epigenetic modification of histones and inhibition of estrogen-activated germ cell proliferation via cyp19a1a downregulation may be two of the key mechanisms which mediate female-to-male sex reversal in zebrafish.

\section{Additional files}

Additional file 1: Detailed methods for qRT-PCR validation of RNA-Seq data. (DOCX 20kb)

Additional file 2: Survival rates and sex ratios of control and MT-treated zebrafish. (DOCX 14kb)

Additional file 3: Read counts, percentage of reads mapped and RPKM. (DOCX 16kb)

Additional file 4: Genes differentially expressed by 2-fold or more in control testes and ovaries. (XLS 1933kb)

Additional file 5: Gene IDs, gene symbols and gene names. (DOCX 18kb)

Additional file 6: Genes differentially expressed by 2-fold or more in 40 dpf testes compared to $60 \mathrm{dpf}$ testes. (XLS 230kb)

Additional file 7: Genes differentially expressed by 2-fold or more in MT-treated testes compared to ovaries. (XLS 3834kb)

Additional file 8: Genes differentially expressed by 2-fold or more in 40 dpf MT-treated testes compared to $60 \mathrm{dpf}$ testes. (XLS 40kb)

Additional file 9: Top ten GeneGo pathways significantly enriched in pairwise comparisons of sex (testes vs. ovaries), treatment (control vs. MT-treated) and time point (40 dpf vs. 60 dpf). (DOCX 20kb)

Additional file 10: Results of qRT-PCR validation of RNA-Seq data. The RNA-seq results are expressed in terms of normalized fold-change (adjusted p-value $<0.05$ ) while qPCR data are expressed as the average relative fold change between samples normalised against the eef1a111 reference gene. Fold change values are compared against the $40 \mathrm{dpf}$ control ovary group (40CO) and $60 \mathrm{dpf}$ control ovary group (60CO). (DOCX $17 \mathrm{~kb})$

\section{Abbreviations}

CO: Control ovary; CT: Control testis; dpf: Days post fertilisation; Esr1: Estrogen Receptor 1; GO: Gene ontology consortium; MT: 17amethyltestosterone; PCR: Polymerase chain reaction; qRT-PCR: Quantitative real-time polymerase chain reaction; RNA-seq: RNA sequencing; RPKM: Reads per kilobase per million mapped reads; Sp: Specificity Protein transcription factor 


\section{Acknowledgements}

We would like to thank Laszlo Orban for the Tg(vas:egfp) zebrafish and his invaluable feedback on drafts of this manuscript, Judith Rodda and Noel Jhinku for their assistance with zebrafish husbandry and Elizabeth Duncan for her guidance regarding the CLC Genomics Workbench software suite.

\section{Funding}

The study was supported by funding to N. Gemmell from the Department of Anatomy, University of Otago. S. Lee was supported by the Department of Anatomy, University of Otago, Postgraduate Award. The funding bodies had no role in the design of the study, data collection and analysis, interpretation of data, and writing of the manuscript.

\section{Availability of data and materials}

All data generated or analysed during this study are included in this published article and its supplementary information files.

\section{Authors' contributions}

$\mathrm{NG}, \mathrm{SL}, J \mathrm{H}$, and MB designed the experiments. SL performed the treatments, sample collection and laboratory work. SL analysed and interpreted the RNASeq data with the assistance of MB and KR. AF performed the zebrafish histology. SL wrote the manuscript with contributions from JH and NG. All authors read and approved the final manuscript.

\section{Ethics approval}

The zebrafish used in this study were derived from the transgenic Tg(vas:egfp) line developed by Krøvel and Olsen 2004. The fish were obtained from Dr. Laszlo Orban of Temasek Life Sciences Laboratory, Singapore, under the New Zealand Ministry of Agriculture and Forestry, Biosecurity New Zealand, permit to import live animals issued on 16 Jun 2010 (Permit No. 2010040155). All animal husbandry and procedures were approved by the University of Otago Animal Ethics Committee (AEC No. 101/09). All experiments were performed in accordance to guidelines for the care and use of animals in research specified by the New Zealand Animal Welfare Act 1999.

\section{Consent for publication}

Not applicable.

\section{Competing interests}

The authors declare no competing financial interests.

\section{Publisher's Note}

Springer Nature remains neutral with regard to jurisdictional claims in published maps and institutional affiliations.

\section{Author details}

'Department of Anatomy, University of Otago, Dunedin, Otago, New Zealand. ${ }^{2}$ Department of Pathology, University of Otago, Dunedin, Otago, New Zealand. ${ }^{3}$ Department of Biochemistry, University of Otago, Dunedin, Otago, New Zealand

Received: 28 February 2017 Accepted: 28 June 2017

Published online: 24 July 2017

\section{References}

1. Segner H, Casanova-Nakayama A, Kase R, Tyler CR. Impact of environmental estrogens on Yfish considering the diversity of estrogen signaling. Gen Comp Endocrinol. 2013;191:190-201.

2. Denslow N, Sepúlveda M: Ecotoxicological effects of endocrine disruptingcompounds on fish reproduction. In: The Fish Oocyte. Netherlands: Springer; 2007. p. 255-322.

3. Leet JK, Gall HE, Sepúlveda MS. A review of studies on androgen and estrogen exposure in fish early life stages: effects on gene and hormonal control of sexual differentiation. J Appl Toxicol. 2011;31(5):379-98.

4. Borg B. Androgens in teleost fishes. Comp Biochem Physiol C: Pharmacol Toxicol Endocrinol. 1994:109(3):219-45.

5. Guiguen Y, Fostier A, Piferrer F, Chang CF. Ovarian aromatase and estrogens: a pivotal role for gonadal sex differentiation and sex change in fish. Gen Comp Endocrinol. 2010;165(3):352-66.

6. Melo MC, van Dijk P, Andersson E, Nilsen TO, Fielldal PG, Male R, Nijenhuis W, Bogerd J, de França $L R$, Taranger $G L$, et al. Androgens directly stimulate spermatogonial differentiation in juvenile Atlantic salmon (Salmo salar). Gen Comp Endocrinol. 2015;211:52-61.

7. Rajakumar A, Senthilkumaran B. Dynamic expression of $11 \beta$-hydroxylase during testicular development, recrudescence and after hCG induction, in vivo and in vitro in catfish, Clarias batrachus. Gen Comp Endocrinol. 2015; 211:69-80.

8. Amer MA, Miura T, Miura C, Yamauchi K. Involvement of sex steroid hormones in the early stages of spermatogenesis in Japanese Huchen (Hucho Perryi). Biol Reprod. 2001;65(4):1057-66.

9. Shi H, Gao T, Liu Z, Sun L, Jiang X, Chen L, Wang D: Blockage of androgen and administration of estrogen induce transdifferentiation of testis into ovary. J Endocrinol. 2017;233(1):65-80.

10. de Waal PP, Wang DS, Nijenhuis WA, Schulz RW, Bogerd J. Functional characterization and expression analysis of the androgen receptor in zebrafish (Danio rerio) testis. Reproduction. 2008:136(2):225-34.

11. Kusakabe M, Kobayashi T, Todo T, Mark Lokman P, Nagahama Y, Young G. Molecular cloning and expression during spermatogenesis of a cDNA encoding testicular 11ß-hydroxylase (P45011ß) in rainbow trout (Oncorhynchus mykiss). Mol Reprod Dev. 2002:62(4):456-69.

12. Kusakabe M, Nakamura I, Young G. 11ß-Hydroxysteroid dehydrogenase complementary deoxyribonucleic acid in rainbow trout: cloning, sites of expression, and seasonal changes in gonads. Endocrinology. 2003;144(6):2534-45

13. Wang $X$, Orban L. Anti-Müllerian hormone and 11 beta-hydroxylase show reciprocal expression to that of aromatase in the transforming gonad of zebrafish males. Dev Dyn. 2007;236(5):1329-38

14. Hossain MS, Larsson A, Scherbak N, Olsson P-E, Orban L. Zebrafish androgen receptor: isolation, molecular, and biochemical characterization. Biol Reprod. 2008;78(2):361-9.

15. Pandian TJ, Sheela SG. Hormonal induction of sex reversal in fish. Aquaculture. 1995;138(1-4):1-22.

16. Yamazaki F. Sex control and manipulation in fish. Aquaculture. 1983;33(1):329-54.

17. Nakamura M, Iwahashi M. Studies on the practical masculinization in Tilapia nilotica by the oral administrator of androgen [hormone, diets]. Bull Jpn Soc Sci Fish. 1982; 48(6):763-69.

18. Seki M, Yokota H, Matsubara H, Maeda M, Tadokoro H, Kobayashi K. Fish full life-cycle testing for androgen methyltestosterone on medaka (Oryzias latipes). Environ Toxicol Chem. 2004;23(3):774-81.

19. Kitano T, Takamune K, Nagahama Y, Abe S-I. Aromatase inhibitor and 17amethyltestosterone cause sex-reversal from genetical females to phenotypic males and suppression of P450 aromatase gene expression in Japanese flounder (Paralichthys olivaceus). Mol Reprod Dev. 2000;56(1):1-5.

20. Piferrer F, Baker IJ, Donaldson EM. Effects of natural, synthetic, Aromatizable, and Nonaromatizable androgens in inducing male sex differentiation in genotypic female Chinook Salmon (Oncorhynchus tshawytscha). Gen Comp Endocrinol. 1993:91(1):59-65.

21. Feist $G$, Yeoh CG, Fitzpatrick MS, Schreck CB. The production of functional sex-reversed male rainbow trout with 17a-methyltestosterone and $11 \beta$ hydroxyandrostenedione. Aquaculture. 1995;131(1-2):145-52.

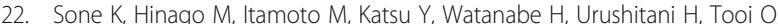
Guillette $L J$ Jr, Iguchi T. Effects of an androgenic growth promoter $17 \beta-$ trenbolone on masculinization of Mosquitofish (Gambusia affinis affinis). Gen Comp Endocrinol. 2005;143(2):151-60.

23. Blázquez M, Piferrer F, Zanuy S, Carrillo M, Donaldson EM. Development of sex control techniques for European sea bass (Dicentrarchus labrax L. ) aquaculture: effects of dietary 17 a-methyltestosterone prior to sex differentiation. Aquaculture. 1995;135(4):329-42.

24. Larsen MG, Baatrup E. Functional behavior and reproduction in androgenic sex reversed zebrafish (Danio rerio). Environ Toxicol Chem. 2010;29(8):1828-33

25. Bhandari RK, Alam MA, Soyano K, Nakamura M. Induction of female-to-male sex change in the honeycomb grouper (Epinephelus merra) by 11 ketotestosterone treatments. Zool Sci. 2006:23(1):65-9.

26. Zhang $W$, Zhang $Y$, Zhang $L$, Zhao $H$, Li $X$, Huang $H$, Lin $H$. The mRNA expression of P450 aromatase, gonadotropin $\beta$-subunits and FTZ-F1 in the orange-spotted grouper (Epinephelus coioides) during 17a-methyltestosterone-induced precocious sex change. Mol Reprod Dev. 2007;74(6):665-73.

27. Sarter K, Papadaki M, Zanuy S, Mylonas CC. Permanent sex inversion in 1 -year-old juveniles of the protogynous dusky grouper (Epinephelus 
marginatus) using controlled-release 17a-methyltestosterone implants. Aquaculture. 2006;256(1-4):443-56.

28. Yeh SL, Dai QC, Chu YT, Kuo CM, Ting YY, Chang CF. Induced sex change, spawning and larviculture of potato grouper, Epinephelus tukula. Aquaculture. 2003;228(1-4):371-81.

29. Li G-L, Liu X-C, Lin H-R. Effects of aromatizable and nonaromatizable androgens on the sex inversion of red-spotted grouper (Epinephelus akaara). Fish Physiol Biochem. 2006;32(1):25-33.

30. Örn S, Holbech H, Madsen TH, Norrgren L, Petersen Gl. Gonad development and vitellogenin production in zebrafish (Danio rerio) exposed to ethinylestradiol and methyltestosterone. Aquat Toxicol. 2003;65(4):397-411.

31. Örn S, Yamani S, Norrgren L. Comparison of Vitellogenin induction, sex ratio, and gonad morphology between Zebrafish and Japanese Medaka after exposure to 17a-Ethinylestradiol and 17 $\beta$-Trenbolone. Arch Environ Contam Toxicol. 2006;51(2):237-43.

32. Baumann L, Knörr S, Keiter S, Nagel T, Rehberger K, Volz S, Oberrauch S, Schiller $\mathrm{V}$, Fenske $\mathrm{M}$, Holbech $\mathrm{H}$, et al. Persistence of endocrine disruption in zebrafish (Danio rerio) after discontinued exposure to the androgen 17 $\beta$ trenbolone. Environ Toxicol Chem. 2014;33(11):2488-96.

33. Morthorst JE, Holbech H, Bjerregaard P. Trenbolone causes irreversible masculinization of zebrafish at environmentally relevant concentrations. Aquat Toxicol. 2010;98(4):336-43.

34. Pandian TJ, Kirankumar S: Recent Advances in Hormonal Induction of SexReversal in Fish. J Appl Aquacult. 2003;13(3):205-30.

35. Budd A, Banh Q, Domingos J, Jerry D. Sex control in fish: approaches, challenges and opportunities for aquaculture. J Mar Sci Eng. 2015;3(2):329.

36. Golan M, Levavi-Sivan B: Artificial masculinization in tilapia involves androgen receptor activation. Gen Comp Endocrinol. 2014;207:50-55.

37. Mor G, Eliza M, Song J, Wiita B, Chen S, Naftolin F. 17a-methyl testosterone is a competitive inhibitor of aromatase activity in jar choriocarcinoma cells and macrophage-like THP-1 cells in culture. J Steroid Biochem Mol Biol. 2001;79(1-5):239-46

38. Takatsu K, Miyaoku K, Roy SR, Murono Y, Sago T, Itagaki H, Nakamura M, Tokumoto T. Induction of female-to-male sex change in adult Zebrafish by Aromatase inhibitor treatment. Sci Rep. 2013;3:3400.

39. Navarro-Martín L, Blázquez M, Piferrer F. Masculinization of the European sea bass (Dicentrarchus labrax) by treatment with an androgen or aromatase inhibitor involves different gene expression and has distinct lasting effects on maturation. Gen Comp Endocrinol. 2009;160(1):3-11.

40. Bhandari RK, Nakamura M, Kobayashi T, Nagahama Y. Suppression of steroidogenic enzyme expression during androgen-induced sex reversal in Nile tilapia (Oreochromis niloticus). Gen Comp Endocrinol. 2006;145(1):20-4.

41. Govoroun M, McMeel OM, D'Cotta H, Ricordel M-J, Smith T, Fostier A, Guiguen Y. Steroid enzyme gene expressions during natural and androgeninduced gonadal differentiation in the rainbow trout. Oncorhynchus mykiss. J Exp Zool Part A. 2001;290(6):558-66.

42. Baron D, Fostier A, Breton B, Guiguen Y. Androgen and estrogen treatments alter steady state messengers RNA (mRNA) levels of testicular steroidogenic enzymes in the rainbow trout, Oncorhynchus mykiss. Mol Reprod Dev. 2005; 71(4):471-9.

43. Baron D, Houlgatte R, Fostier A, Guiguen Y. Expression profiling of candidate genes during ovary-to-testis trans-differentiation in rainbow trout masculinized by androgens. Gen Comp Endocrinol. 2008;156(2):369-78.

44. Baron D, Montfort J, Houlgatte R, Fostier A, Guiguen Y. Androgen-induced masculinization in rainbow trout results in a marked dysregulation of early gonadal gene expression profiles. BMC Genomics. 2007;8(1):357.

45. Vizziano D, Baron D, Randuineau G, Mahè S, Cauty C, Guiguen Y. Rainbow trout Gonadal Masculinization induced by inhibition of estrogen synthesis is more physiological than Masculinization induced by androgen supplementation. Biol Reprod. 2008;78(5):939-46.

46. Martyniuk CJ, Denslow ND. Exploring androgen-regulated pathways in Teleost fish using Transcriptomics and proteomics. Integr Comp Biol. 2012;52(5):695-704.

47. Shi $Y$, Liu $X$, Zhang $H$, Zhang $Y$, Lu D, Lin H. Molecular identification of an androgen receptor and its changes in mRNA levels during 17amethyltestosterone-induced sex reversal in the orange-spotted grouper Epinephelus coioides. Comp Biochem Physiol B: Biochem Mol Biol. 2012;163(1):43-50.

48. Van den Belt K, Verheyen R, Witters H. Reproductive effects of Ethynylestradiol and 4t-Octylphenol on the Zebrafish ( Danio rerio ). Arch Environ Contam Toxicol. 2001;41(4):458-67.
49. Fenske M, Maack G, Schäfers C, Segner $H$. An environmentally relevant concentration of estrogen induces arrest of male gonad development in zebrafish, Danio rerio. Environ Toxicol Chem. 2005;24(5):1088-98.

50. Schafers C, Teigeler M, Wenzel A, Maack G, Fenske M, Segner H. Concentration- and time-dependent effects of the synthetic estrogen, 17aethinylestradiol, on Reproductive capabilities of the Zebrafish, Danio rerio. J Toxicol Environ Health A. 2007;70(9):768-79.

51. Larsen MG, Bilberg K, Baatrup E. Reversibility of estrogenic sex changes in zebrafish (Danio rerio). Environ Toxicol Chem. 2009;28(8):1783-5.

52. Baumann L, Knörr S, Keiter S, Nagel T, Segner H, Braunbeck T. Prochloraz causes irreversible masculinization of zebrafish (Danio rerio). Environ Sci Pollut Res. 2015;22(21):16417-22.

53. Baumann L, Knörr S, Keiter S, Rehberger K, Volz S, Schiller V, Fenske M, Holbech $H$, Segner $H$, Braunbeck T. Reversibility of endocrine disruption in zebrafish (Danio rerio) after discontinued exposure to the estrogen $17 a-$ ethinylestradiol. Toxicol Appl Pharmacol. 2014;278(3):230-7.

54. Luzio A, Matos M, Santos D, Fontaínhas-Fernandes AA, Monteiro SM, Coimbra AM. Disruption of apoptosis pathways involved in zebrafish gonad differentiation by 17a-ethinylestradiol and fadrozole exposures. Aquat Toxicol. 2016;177:269-84.

55. Luzio A, Monteiro SM, Garcia-Santos S, Rocha E, Fontaínhas-Fernandes AA, Coimbra AM. Zebrafish sex differentiation and gonad development after exposure to $17 a$-ethinylestradiol, fadrozole and their binary mixture: a stereological study. Aquat Toxicol. 2015;166:83-95.

56. Luzio A, Monteiro SM, Rocha E, Fontaínhas-Fernandes AA, Coimbra AM. Development and recovery of histopathological alterations in the gonads of zebrafish (Danio rerio) after single and combined exposure to endocrine disruptors (17a-ethinylestradiol and fadrozole). Aquat Toxicol. 2016;175:90-105.

57. Luzio A, Santos D, Fontaínhas-Fernandes AA, Monteiro SM, Coimbra AM Effects of 17 a-ethinylestradiol at different water temperatures on zebrafish sex differentiation and gonad development. Aquat Toxicol. 2016;174:22-35

58. Wilson CA, High SK, McCluskey BM, Amores A, Y-I Y, Titus TA, Anderson J L Batzel P, Carvan MJ, Schartl M, et al. Wild sex in Zebrafish: loss of the natural sex determinant in domesticated strains. Genetics. 2014;198(3):1291-308.

59. Liew WC, Bartfai R, Lim Z, Sreenivasan R, Siegfried KR, Orban L. Polygenic Sex Determination System in Zebrafish. PLoS One. 2012;7(4):e34397.

60. Uchida D, Yamashita M, Kitano T, Iguchi T. An aromatase inhibitor or high water temperature induce oocyte apoptosis and depletion of P450 aromatase activity in the gonads of genetic female zebrafish during sex-reversal. Comp Biochem Physiol A Mol Integr Physiol. 2004;137:11-20.

61. Ribas L, Liew WC, Díaz N, Sreenivasan R, Orbán L, Piferrer F. Heatinduced masculinization in domesticated zebrafish is family-specific and yields a set of different gonadal transcriptomes. Proc Natl Acad Sci. 2017;114(6):E941-50.

62. Shang EHH, Yu RMK, Wu RSS. Hypoxia affects sex differentiation and development, leading to a male-dominated population in Zebrafish (Danio rerio). Environ Sci Technol. 2006:40(9):3118-22.

63. Ribas L, Valdivieso A, Díaz N, Piferrer F: On the proper rearing density in domesticated zebrafish to avoid unwanted masculinization. Links with the stress response. J Exp Biol. 2017;220(6):1056-64.

64. Nusslein-Volhard C, Dahm R: Zebrafish: a practical approach.: Oxford University Press, Oxford, UK; 2002.

65. Brown AR, Bickley LK, Ryan TA, Paull GC, Hamilton PB, Owen SF, Sharpe $A D$, Tyler $C R$. Differences in sexual development in inbred and outbred zebrafish (Danio rerio) and implications for chemical testing. Aquat Toxicol. 2012;112-113:27-38.

66. Lawrence C, Ebersole J, Kesseli R. Rapid growth and out-crossing promote female development in zebrafish (Danio rerio). Environ Biol Fish. 2008;81(2):239-46.

67. Takahashi H. Juvenile hermaphroditism in the zebrafish, Brachydanio rerio. Bull Fac Fish Hokkaido Univ. 1977;28(2):57-65.

68. Maack G, Segner H. Morphological development of the gonads in zebrafish. J Fish Biol. 2003;62(4):895-906.

69. Wang X, Bartfai R, Sleptsova-Freidrich I, Orban L. The timing and extent of 'juvenile ovary' phase are highly variable during zebrafish testis differentiation. J Fish Biol. 2007;70:33-44.

70. Lau ES-W, Zhang Z, Qin M, Ge W. Knockout of Zebrafish ovarian Aromatase Gene (cyp19a1a) by TALEN and CRISPR/Cas9 leads to all-male offspring due to failed ovarian differentiation. Sci Rep. 2016;6:37357. 
71. Uchida D, Yamashita M, Kitano T, Iguchi T. Oocyte apoptosis during the transition from ovary-like tissue to testes during sex differentiation of juvenile zebrafish. J Exp Biol. 2002;205:711-8.

72. Fenske $M$, Segner $H$. Aromatase modulation alters gonadal differentiation in developing zebrafish (Danio rerio). Aquat Toxicol. 2004;67(2):105-26.

73. Krøvel AV, Olsen LC. Sexual dimorphic expression pattern of a splice variant of zebrafish vasa during gonadal development. Dev Biol. 2004;271(1):190-7.

74. Filby AL, Ortiz-Zarragoitia M, Tyler CR. The vas::egfp transgenic zebrafish: a practical model for studies on the molecular mechanisms by which environmental estrogens affect gonadal sex differentiation. Environ Toxicol Chem. 2014;33(3):602-5.

75. Chen W, Ge W. Gonad differentiation and puberty onset in the zebrafish: evidence for the dependence of puberty onset on body growth but not age in females. Mol Reprod Dev. 2013;80(5):384-92.

76. Westerfield M: The zebrafish book: a guide for the laboratory use of zebrafish (Brachydanio rerio). 4th ed. Eugene: University of Oregon press; 2000.

77. Filby AL, Ortiz-Zarragoitia M, Tyler CR. The vas::egfp transgenic zebrafish: a practical model for studies on the molecular mechanisms by which environmental estrogens affect gonadal sex differentiation. Environ Toxicol Chem. 2013:33(3):602-5.

78. Selman K, Wallace RA, Sarka A, Qi X. Stages of oocyte development in the zebrafish, Brachydanio rerio. J Morphol. 1993; 218(2):203-24.

79. Kinnberg $K$, Holbech $H$, Petersen $G l$, Bjerregaard P. Effects of the fungicide prochloraz on the sexual development of zebrafish (Danio rerio). Comp Biochem Physiol C Pharmacol Toxicol Endocrinol. 2007;145(2):165-70.

80. Schulz RW, de França LR, Lareyre J-J, LeGac F, Chiarini-Garcia H, Nobrega RH, Miura T. Spermatogenesis in fish. Gen Comp Endocrinol. 2010;165(3):390-411.

81. Andrews S. FastQC: a quality control tool for high throughput sequence data. 2010. http://www.bioinformatics.babraham.ac.uk/projects/fastqc.

82. Mortazavi A, Williams BA, McCue K, Schaeffer L, Wold B. Mapping and quantifying mammalian transcriptomes by RNA-Seq. Nat Methods. 2008:5(7):621-8.

83. Baggerly KA, Deng L, Morris JS, Aldaz CM. Differential expression in SAGE: accounting for normal between-library variation. Bioinformatics. 2003;19(12):1477-83.

84. Benjamini $Y$, Hochberg Y. Controlling the false discovery rate: a practical and powerful approach to multiple testing. J R Stat Soc Ser B Methodol. 1995;57(1):289-300.

85. Gene Ontology Consortium: going forward. Nucleic Acids Res. 2015;43(D1): D1049-56.

86. Tang R, Dodd A, Lai D, McNabb WC, Love DR. Validation of Zebrafish (Danio rerio) reference genes for quantitative real-time RT-PCR normalization. Acta Biochim Biophys Sin. 2007;39(5):384-90.

87. McCurley AT, Callard GV. Characterization of housekeeping genes in zebrafish: male-female differences and effects of tissue type, developmental stage and chemical treatment. BMC Mol Biol. 2008;9:102.

88. Siegfried KR, Nüsslein-Volhard C. Germ line control of female sex determination in zebrafish. Dev Biol. 2008:324(2):277-87.

89. Vandesompele J, De Preter K, Pattyn F, Poppe B, Van Roy N, De Paepe A, Speleman F. Accurate normalization of real-time quantitative RT-PCR data by geometric averaging of multiple internal control genes. Genome Biol. 2002;3(7):research0034.0031-11.

90. Webster KA, Schach U, Ordaz A, Steinfeld JS, Draper BW, Siegfried KR: Dmrt is necessary for male sexual development in zebrafish. Dev Biol. 2016;422(1): 33-46.

91. Kobayashi T, Kajiura-Kobayashi H, Guan G, Nagahama Y. Sexual dimorphic expression of DMRT1 and Sox9a during gonadal differentiation and hormone-induced sex reversal in the teleost fish Nile tilapia (Oreochromis niloticus). Dev Dyn. 2008;237(1):297-306

92. Horie $Y$, Myosho T, Sato T, Sakaizumi M, Hamaguchi S, Kobayashi T. Androgen induces gonadal soma-derived factor, Gsdf, in XX gonads correlated to sex-reversal but not Dmrt1 directly, in the teleost fish, northern medaka (Oryzias sakaizumii). Mol Cell Endocrinol. 2016;436:141-9.

93. Díaz N, Piferrer F. Lasting effects of early exposure to temperature on the gonadal transcriptome at the time of sex differentiation in the European sea bass, a fish with mixed genetic and environmental sex determination. BMC Genomics. 2015;16(1):679.

94. Poonlaphdecha S, Pepey E, Canonne M, de Verdal H, Baroiller J-F, D'Cotta H. Temperature induced-masculinisation in the Nile tilapia causes rapid upregulation of both dmrt1 and amh expressions. Gen Comp Endocrinol. 2013;193:234-42
95. Hattori RS, Gould RJ, Fujioka T, Saito T, Kurita J, Strüssmann CA, Yokota M, Watanabe S. Temperature-dependent sex determination in Hd-rR Medaka Oryzias latipes: gender sensitivity, thermal threshold, critical period, and DMRT1 expression profile. Sex Dev. 2007;1(2):138-46.

96. Fernandino II, Hattori RS, Shinoda T, Kimura H, Strobl-Mazzulla PH, Strussmann CA, Somoza GM. Dimorphic expression of dmrt1 and cyp19a1 (ovarian aromatase) during early gonadal development in pejerrey. Odontesthes bonariensis. Sex Dev. 2008;2(6):316-24.

97. Rodríguez-Marí A, Yan YL, BreMiller RA, Wilson C, Cañestro C, Postlethwait $J$ H. Characterization and expression pattern of zebrafish anti-Müllerian hormone (amh) relative to sox9a, sox9b, and cyp19a1a, during gonad development. Gene Expr Patterns. 2005;5(5):655-67.

98. Morinaga C, Saito D, Nakamura S, Sasaki T, Asakawa S, Shimizu N, Mitani H, Furutani-Seiki M, Tanaka M, Kondoh $H$. The hotei mutation of medaka in the anti-Müllerian hormone receptor causes the dysregulation of germ cell and sexual development. Proc Natl Acad Sci U S A. 2007;104(23):9691-6.

99. Nakamura S, Watakabe I, Nishimura T, Picard J-Y, Toyoda A, Taniguchi Y, di Clemente N, Tanaka M. Hyperproliferation of mitotically active germ cells due to defective anti-Müllerian hormone signaling mediates sex reversal in medaka. Development. 2012;139(13):2283.

100. Shibata Y, Paul-Prasanth B, Suzuki A, Usami T, Nakamoto M, Matsuda M, Nagahama Y. Expression of gonadal soma derived factor (GSDF) is spatially and temporally correlated with early testicular differentiation in medaka. Gene Expr Patterns. 2010;10(6):283-9.

101. Zhang X, Guan G, Li M, Zhu F, Liu Q, Naruse K, Herpin A, Nagahama Y, Li J, Hong Y. Autosomal gsdf acts as a male sex initiator in the fish medaka. Sci Rep. 2016;6:19738.

102. Chakraborty T, Zhou LY, Chaudhari A, Iguchi T, Nagahama Y. Dmy initiates masculinity by altering Gsdf/Sox9a2/Rspo1 expression in medaka (Oryzias latipes). Sci Rep. 2016;6:19480.

103. Imai T, Saino K, Matsuda M. Mutation of Gonadal soma-derived factor induces medaka XY gonads to undergo ovarian development. Biochem Biophys Res Commun. 2015;467(1):109-14.

104. Kah O, Trudeau VL, Sloley BD, Chang JP, Dubourg P, Yu KL, Peter RE. Influence of GABA on gonadotrophin release in the goldfish. Neuroendocrinology. 1992;55(4):396-404.

105. Trudeau VL, Sloley BD, Peter RE. GABA stimulation of gonadotropin-II release in goldfish: involvement of GABAA receptors, dopamine, and sex steroids. Am J Physiol Regul Integr Comp Physiol. 1993;265(2):R348-55.

106. Senthilkumaran B, Okuzawa K, Gen K, Kagawa H. Effects of serotonin, GABA and Neuropeptide $Y$ on Seabream Gonadotropin releasing hormone release in vitro from Preoptic-anterior hypothalamus and pituitary of red Seabream, Pagrus major. J Neuroendocrinol. 2001;13(5):395-400.

107. Bryant AS, Greenwood AK, Juntti SA, Byrne AE, Fernald RD. Dopaminergic inhibition of gonadotropin-releasing hormone neurons in the cichlid fish Astatotilapia burtoni. J Exp Biol. 2016;219(24):3861-5.

108. Mañanos EL, Anglade I, Chyb J, Saligaut C, Breton B, Kah O. Involvement of $\gamma$-aminobutyric acid in the control of $\mathrm{GtH}-1$ and $\mathrm{GtH}-2$ secretion in male and female rainbow trout. Neuroendocrinology. 1999;69(4):269-80.

109. Trudeau V, Spanswick D, Fraser E, Lariviere K, Crump D, Chiu S, MacMillan M, Schulz R. The role of amino acid neurotransmitters in the regulation of pituitary gonadotropin release in fish. Biochem Cell Biol. 2000;78(3):241-59.

110. Chang JP, Peter RE. Effects of dopamine on gonadotropin release in female goldfish. Carassius auratus. Neuroendocrinology. 1983;36(5):351-7.

111. Geigerseder C, Doepner R, Thalhammer A, Frungieri MB, Gamel-Didelon K, Calandra RS, Köhn FM, Mayerhofer A. Evidence for a GABAergic system in rodent and human testis: local GABA production and GABA receptors. Neuroendocrinology. 2003;77(5):314-23.

112. Geigerseder C, Doepner RFG, Thalhammer A, Krieger A, Mayerhofer A. Stimulation of TM3 Leydig cell proliferation via GABA(a )receptors: a new role for testicular GABA. Reprod Biol Endocrinol. 2004;2:13.

113. Ritta M, Calandra R. Occurrence of GABA in rat testis and its effect on androgen production. Adv Biochem Psychopharmacol. 1986;42:291.

114. Ritta MN, Campos MB, Calandra RS. Effect of GABA and benzodiazepines on testicular androgen production. Life Sci. 1987;40(8):791-8.

115. Frungieri MB, Gonzalez-Calvar SI, Chandrashekar V, Rao JN, Bartke A, Calandra RS. Testicular gamma-aminobutyric acid and circulating androgens in Syrian and Djungarian hamsters during sexual development. Int J Androl. 1996;19(3):164-70 
116. Otth C, Torres M, Ramírez A, Fernandez JC, Castro M, Rauch MC, Brito M, Yañez AJ, Rodríguez-Gil J-E, Slebe JC, et al. Novel identification of peripheral dopaminergic D2 receptor in male germ cells. J Cell Biochem. 2007;100(1):141-50.

117. Ramírez AR, Castro MA, Angulo C, Ramió L, Rivera MM, Torres M, Rigau T, Rodríguez-Gil JE, Concha II. The presence and function of dopamine type 2 receptors in boar sperm: a possible role for dopamine in viability, capacitation, and modulation of sperm motility. Biol Reprod. 2009;80(4):753-61.

118. Zohar Y, Mylonas CC. Endocrine manipulations of spawning in cultured fish: from hormones to genes. Aquaculture. 2001;197(1-4):99-136.

119. Lin H-R, Van Der Kraak G, Zhou X-J, Liang J-Y, Peter RE, Rivier JE, Vale WW. Effects of [D-Arg 6, Trp 7, Leu 8, pro 9 NEt]-luteinizing hormone-releasing hormone (sGnRH-A) and [D-ala 6, pro 9 NEt]-luteinizing hormone-releasing hormone (LHRH-A), in combination with pimozide or domperidone, on gonadotropin release and ovulation in the Chinese loach and common carp. Gen Comp Endocrinol. 1988;69(1):31-40.

120. Hales DB. Testicular macrophage modulation of Leydig cell steroidogenesis. J Reprod Immunol. 2002;57(1):3-18.

121. Svechnikov KV, Sultana T, Söder O. Age-dependent stimulation of Leydig cell steroidogenesis by interleukin-1 isoforms. Mol Cell Endocrinol. 2001;182(2):193-201.

122. Huleihel M, Lunenfeld E. Regulation of spermatogenesis by paracrine/ autocrine testicular factors. Asian J Androl. 2004;6(3):259-68.

123. Verhoeven G, Cailleau J, Van Damme J, Billiau A. Interleukin-1 stimulates steroidogenesis in cultured rat Leydig cells. Mol Cell Endocrinol. 1988;57(1-2):51-60.

124. Warren D, Pasupuleti V, Lu Y, Platler B, Horton R. Tumor necrosis factor and interleukin-1 stimulate testosterone secretion in adult male rat Leydig cells in vitro. J Androl. 1989;11(4):353-60.

125. Meinhardt A, Bacher M, MCFarlane JR, Metz CN, Seitz J, Hedger MP, De Kretser D, Bucala R. Macrophage migration inhibitory factor production by Leydig cells: evidence for a role in the regulation of testicular function. Endocrinol. 1996;137(11):5090-5.

126. Anahara R, Toyama Y, Koda M, Honma S, Nishihira J, Toshimori K, Mori C. Deletion of macrophage migration inhibitory factor gene induces down regulation of sex hormones and ultrastructural abnormalities in mouse testes. Reprod Toxicol. 2006;21(2):167-70.

127. Huleihel M, Abofoul-Azab M, Abarbanel Y, Einav I, Levitas E, Lunenfeld E. Production of macrophage inhibitory factor (MIF) by primary Sertoli cells; its possible involvement in migration of Spermatogonial cells. J Cell Physiol. 2017 .

128. Meinhardt A, Bacher M, Wennemuth G, Eickhoff R, Hedger M. Macrophage migration inhibitory factor (MIF) as a paracrine mediator in the interaction of testicular somatic cells. Andrologia. 2000;32(1):46-8.

129. Huleihel M, Lunenfeld E, Blindman A, Prinsloo I, Potashnik G. Over expression of interleukin-1 $\alpha$, interleukin-1 $\beta$ and interleukin-1 receptor antagonist in testicular tissues from sexually immature mice as compared to adult mice. Eur Cytokine Netw. 2003;14(1):27-33.

130. Huleihel M, Lunenfeld E: Involvement of intratesticular IL-1 system in the regulation of Sertoli cell functions. Mol Cell Endocrinol 2002, 187(1-2):125-132

131. Petersen C, Boitani C, Fröysa B, Söder O. Interleukin-1 is a potent growth factor for immature rat Sertoli cells. Mol Cell Endocrinol. 2002;186(1):37-47.

132. Yano A, Guyomard R, Nicol B, Jouanno E, Quillet E, Klopp C, Cabau C, Bouchez O, Fostier A, Guiguen Y. An immune-related Gene evolved into the master sex-determining Gene in rainbow trout. Oncorhynchus mykiss. Curr Biol. 2012;22(15):1423-8.

133. Drabent B, Bode C, Doenecke D. Structure and expression of the mouse testicular $\mathrm{H} 1$ histone gene $(\mathrm{H} 1 \mathrm{t})$. BBA - Gene Structure and Expression. 1993;1216(2):311-3.

134. Montellier E, Boussouar F, Rousseaux S, Zhang K, Buchou T, Fenaille F, Shiota H, Debernardi A, Héry P, Curtet S, et al. Chromatin-to-nucleoprotamine transition is controlled by the histone H2B variant TH2B. Genes Dev. 2013;27(15):1680-92.

135. Urahama T, Horikoshi N, Osakabe A, Tachiwana H, Kurumizaka H. Structure of human nucleosome containing the testis-specific histone variant TSH2B. Acta Crystallogr Sect F Struct Biol Cryst Commun. 2014;70(Pt 4):444-9.

136. Ueda J, Harada A, Urahama T, Machida S, Maehara K, Hada M, Makino Y, Nogami J, Horikoshi N, Osakabe A, et al. Testis-specific Histone variant H3t Gene is essential for entry into spermatogenesis. Cell Rep. 2017:18(3):593-600.

137. Maehara K, Harada A, Sato Y, Matsumoto M, Nakayama Kl, Kimura H, Ohkawa $Y$. Tissue-specific expression of histone $\mathrm{H} 3$ variants diversified after species separation. Epigenetics Chromatin. 2015;8(1):35.
138. Yan W, Ma L, Burns KH, Matzuk MM. HILS1 is a spermatid-specific linker histone $\mathrm{H} 1$-like protein implicated in chromatin remodeling during mammalian spermiogenesis. Proc Natl Acad Sci. 2003;100(18):10546-51.

139. Bao J, Bedford MT. Epigenetic regulation of the histone-to-protamine transition during spermiogenesis. Reproduction. 2016;151(5):R55-70.

140. Rathke C, Baarends WM, Awe S, Renkawitz-Pohl R. Chromatin dynamics during spermiogenesis. BBA - Gene Regulatory Mechanisms. 2014;1839(3): 155-68.

141. Govin J, Caron C, Lestrat C, Rousseaux S, Khochbin S. The role of histones in chromatin remodelling during mammalian spermiogenesis. Eur J Biochem. 2004;271(17):3459-69.

142. Dranow DB, Hu K, Bird AM, Lawry ST, Adams MT, Sanchez A, Amatruda JF, Draper BW. Bmp15 is an Oocyte-produced signal required for maintenance of the adult female sexual phenotype in Zebrafish. PLoS Genet. 2016;12(9):e1006323.

143. Sreenivasan R, Jiang J, Wang X, Bartfai R, Kwan HY, Christoffels A, Orban L. Gonad differentiation in zebrafish is regulated by the canonical wnt signaling pathway. Biol Reprod. 2014;90(2):45.

144. Zhou L, Charkraborty T, Zhou Q, Mohapatra S, Nagahama Y, Zhang Y. Rspo1-activated signalling molecules are sufficient to induce ovarian differentiation in XY medaka (Oryzias latipes). Sci Rep. 2016;6:19543.

145. Zhou LY, Charkraborty T, Yu XG, Wu LM, Liu G, Mohapatra S, Wang DS, Nagahama Y: R-spondins are involved in the ovarian differentiation in a teleost, medaka (Oryzias latipes). BMC Dev Biol. 2012;12(1):36.

146. Nicol B, Guiguen Y. Expression profiling of Wnt signaling genes during Gonadal differentiation and Gametogenesis in rainbow trout. Sex Dev. 2011;5(6):318-29.

147. Fan Z, You F, Wang L, Weng S, Wu Z, Hu J, Zou Y, Tan X, Zhang P. Gonadal Transcriptome analysis of male and female olive flounder (Paralichthys olivaceus). Biomed Res Int. 2014;2014:10.

148. Fernandino Il, Hattori RS, Kishii A, Strüssmann CA, Somoza GM. The Cortisol and androgen pathways cross talk in high temperature-induced Masculinization: the $11 \beta$-Hydroxysteroid Dehydrogenase as a key enzyme. Endocrinology. 2012;153(12):6003-11.

149. Rodriguez-Mari A, Cañestro C, BreMiller RA, Nguyen-Johnson A, Asakawa K, Kawakami K, Postlethwait JH. Sex reversal in Zebrafish fand mutants is caused by Tp53-mediated germ cell apoptosis. PLoS Genet. 2010;6(7):e1001034.

150. Pradhan A, Khalaf H, Ochsner SA, Sreenivasan R, Koskinen J, Karlsson M, Karlsson J, McKenna NJ, Orban L, Olsson P-E: Activation of NF-KB prevents the transition from juvenile ovary to testis and promotes ovarian development in zebrafish. J Biol Chem. 2012; 287:37926-38.

151. Slanchev K. Stebler Jr, de la Cueva-Méndez G, Raz E: development without germ cells: the role of the germ line in zebrafish sex differentiation. Proc Natl Acad Sci U S A. 2005;102(11):4074-9.

152. Dranow DB, Tucker RP, Draper BW. Germ cells are required to maintain a stable sexual phenotype in adult zebrafish. Dev Biol. 2013;376(1):43-50.

153. Pentikäinen V, Erkkilä K, Suomalainen L, Parvinen M, Dunkel L. Estradiol acts as a germ cell survival factor in the human testis in vitro. J Clin Endocrinol Metab. 2000;85(5):2057-67.

154. Delbès G, Levacher C, Pairault C, Racine C, Duquenne C, Krust A, Habert R. Estrogen receptor $\beta$-mediated inhibition of male germ cell line development in mice by endogenous estrogens during Perinatal life. Endocrinology. 2004;145(7):3395-403.

155. Liew WC, Orbán L. Zebrafish sex: a complicated affair. Brief Funct Genomics. 2013;13(2):172-87.

156. Tzung K-W, Goto R, Saju Jolly M, Sreenivasan R, Saito T, Arai K, Yamaha E, Hossain Mohammad S, Calvert Meredith EK, Orbán L. Early depletion of primordial germ cells in Zebrafish promotes testis formation. Stem Cell Reports. 2015:4(1):61-73.

157. Houwing S, Kamminga LM, Berezikov E, Cronembold D, Girard A, van den Elst H, Filippov DV, Blaser H, Raz E, Moens CB, et al. A role for Piwi and piRNAs in germ cell maintenance and Transposon silencing in Zebrafish. Cell. 2007:129(1):69-82.

158. Baroiller JF, D'Cotta $H$. The reversible sex of Gonochoristic fish: insights and consequences. Sex Dev. 2016;10(5-6):242-66.

159. Duffy TA, Picha ME, Won ET, Borski RJ, McElroy AE, Conover DO. Ontogenesis of gonadal aromatase gene expression in atlantic silverside (Menidia menidia) populations with genetic and temperature-dependent sex determination. J Exp Zool A Ecol Genet Physiol. 2010;313A(7):421-31.

160. Piferrer F, Ribas L, Díaz N. Genomic approaches to study genetic and environmental influences on fish sex determination and differentiation. Mar Biotechnol. 2012:14(5):591-604 